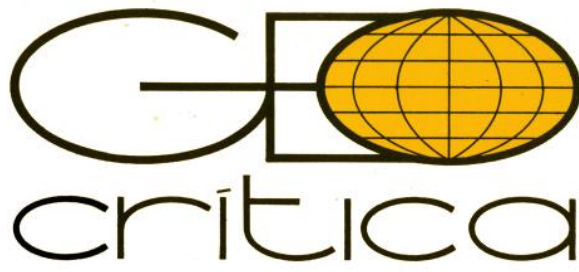

\title{
ALTERNATIVAS À ESCASSEZ E A CRISE HÍDRICA PRODUZIDAS POR POLÍTICAS NEOLIBERAIS NO RIO DE JANEIRO
}

\author{
Hindenburgo Francisco Pires \\ Departamento de Geografia Humana, Universidade do Estado do Rio de Janeiro \\ hindenburgo@uerj.br \\ Danilo Rocha Cerqueira \\ Doutorando do PPGEO, Universidade do Estado do Rio de Janeiro \\ danilocerqueira09@yahoo.com.br
}

\section{Alternativas à escassez e a crise hídrica produzidas por políticas neoliberais no Rio de Janeiro (Resumo)}

A escassez hídrica tal qual iremos tratar nesse artigo, pode ser entendida como um processo generalizado de produção de disparidades e de exacerbação das desigualdades sociais. A falta constante de acesso a bens tangíveis e não tangíveis, de objetos, produtos, recursos, tecnologias, acesso a espaços e serviços considerados essenciais para a maioria da humanidade, é o que caracteriza, no período atual, o que denominamos como escassez. A escassez de água será tratada também como sendo decorrente do crescimento das desigualdades e vinculada à expansão do capitalismo periférico e à urbanização tardia, típica das economias "emergentes". Nesse sentido, nossos objetivos são, em primeiro lugar, analisar a escassez hídrica na Região Metropolitana do Rio de Janeiro (RMRJ), sob a gestão da Companhia Estadual de Águas e Esgotos do Rio de Janeiro (CEDAE), empresa responsável pelo fornecimento precário de água potável à maioria dos municípios da RMRJ; em segundo lugar, apresentar um quadro com um conjunto de ações políticas, possibilidades e estratégias políticas para a gestão e o enfrentamento da escassez hídrica, por meio de sistematização de recomendações selecionadas, a partir de práticas e estudos técnicos potencialmente compatíveis, em que serão propostas medidas, estratégias e escalas de ação, como alternativas à crise hídrica produzida por políticas neoliberais, que favorecem a distribuição espacial desigual da água no Rio de Janeiro.

Palavras chave: Crise hídrica; Políticas públicas; Bacia Hidrográfica do Rio Guandu; Município do Rio de Janeiro. 


\section{Alternatives to scarcity and the water crisis produced by neoliberal policies in Rio de Janeiro (Abstract)}

Water scarcity, as we will discuss in this article, can be understood as a generalized process of producing disparities and exacerbating social inequalities. The constant lack of access to tangible and non-tangible goods, objects, products, resources, technologies, access to spaces and services considered essential for the majority of humanity, is what characterizes, in the current period, what we call as scarcity. Water scarcity will also be treated as a result of the growth of inequalities and linked to the expansion of peripheral capitalism and late urbanization, typical of "emerging" economies. In this sense, our objectives are, first of all, to analyze the water scarcity in the metropolitan region of Rio de Janeiro (RMRJ), under the management of the State Water and Sewage Company of Rio de Janeiro (CEDAE), company responsible for the precarious supply of drinking water the majority of RMRJ municipalities; secondly, to present a table with a set of political actions, possibilities and political strategies for the management and coping with water scarcity, through the systematization of selected recommendations, from potentially compatible practices and technical studies, in which they will be proposed measures, strategies and scales of action, as alternatives to the water crisis produced by neoliberal policies, which favor the uneven spatial distribution of water in Rio de Janeiro.

Keywords: Water crisis; Public policies; Guandu River Basin; Rio de Janeiro Municipality.

\section{Introdução}

O esgotamento do modelo urbano capitalista de uso e consumo de recursos naturais, baseado na lógica hegemônica extrativista e depredadora de exploração dos elementos da natureza, está acentuando as assimetrias em duas importantes metrópoles brasileiras: São Paulo e Rio de Janeiro, agravando também os problemas no fornecimento urbano de água e esgotamento sanitário.

Esse modelo de longa duração, gerado no capitalismo pela "destruição criativa" da natureza", vem produzindo a escassez hídrica ou hidrossocial ${ }^{2}$ e vem se intensificando com o aquecimento global e as mudanças climáticas em escala planetária.

A escassez de água se tornou estratégia, usada pela racionalidade neoliberal hegemônica ${ }^{3}$, para produzir necessidades e, dialeticamente, produzir técnicas pseudo-mitigadoras de suas próprias consequências, através de empresas inseridas no mercado capitalista de serviços e livre comércio, fazendo com que a situação de escassez atingisse, de forma distinta e seletiva, determinados grupos sociais.

A escassez, enquanto fenômeno social, foi incorporada pelo atual sistema econômico para manter o sistema capitalista de dominação das sociedades globais a tudo que é engendrado pelo seu poder. Ela também foi uma das justificativas utilizadas contra o adensamento e a concentração urbana, formadoras de poderosas economias de aglomeração.

Quando a dinâmica referente ao cotidiano das populações está vinculada à lógica mercantilista e neoliberal da escassez dominante, relações e práticas, que resultam no agravamento da

\footnotetext{
${ }^{1}$ Harvey 2011, p.151.

${ }^{2}$ Britto et al, 2016, p.3 <https://www.scielo.br/pdf/asoc/v19n1/pt_1809-4422-asoc-19-01-00183.pdf>.

${ }^{3}$ Santos 2000, p. 128.
} 
problemática socioambiental urbana, tende a se estabelecer na provisão de serviços e bens de consumo coletivo.

O próprio surgimento dos conceitos de desenvolvimento sustentável e sustentabilidade, que eclodiram no final do século XX, estava alicerçado na questão do agravamento da provisão ou oferta de bens e serviços coletivos. Esse processo pode ser entendido a partir das possibilidades de apropriação e de criação de bens e coisas, que podem estar relacionadas a diversos conceitos e temas como, por exemplo: disponibilidade de recursos naturais, ofertas de serviços de consumo coletivos, conhecimento, técnica e tecnologia, etc. Esses temas estão inseridos em dimensões cujos desdobramentos sociais apresentam características quanto à forma, à escala e à situação-tipo do processo de escassez.

Nesse sentido, os objetivos deste trabalho são, em primeiro lugar, debater e contribuir para analisar a escassez hídrica na Região Metropolitana do Rio de Janeiro (RMRJ), sob a gestão da Companhia Estadual de Águas e Esgotos do Rio de Janeiro (CEDAE), empresa responsável pelo fornecimento precário de água potável à maioria dos municípios da RMRJ; em segundo lugar, propor ações, possibilidades e estratégias políticas para a gestão e o enfrentamento da escassez hídrica do sistema hídrico da bacia hidrográfica do Rio Paraíba do Sul ${ }^{4}$, Região Hidrográfica III (RH III), que se estende até a sua transposição na Bacia Hidrográfica do Rio Guandu, Região Hidrográfica II $\left(\mathrm{RH}\right.$ II) ${ }^{5}$ (Figura 1), por meio de sistematização de recomendações selecionadas, a partir de práticas e estudos técnicos potencialmente compatíveis, em um quadro de medidas, estratégias e escalas de ação, a partir de referências e formulações baseadas em várias pesquisas científicas.

Para cumprir essa última meta, foi realizado um levantamento no recorte espacial das regiões hidrográficas RH III e RH II e também das estratégias de gestão e provisão dos serviços de abastecimento público nos períodos de crise hídrica de 2013 a 2015. De acordo com as características do processo de escassez hídrica, foram considerados os problemas relacionados à falta de água para consumo ou uso, e a situação-tipo dos atores que sofrem com o precário fornecimento de água.

\footnotetext{
${ }^{4}$ Segundo a Agência Nacional de Águas (ANA): “O rio Paraíba do Sul resulta da confluência dos rios Paraibuna e Paraitinga, que nascem no estado de São Paulo e seus cursos d'água percorrem a região de Minas Gerais até desaguar no Oceano Atlântico, em São João da Barra (RJ). No leito do rio, estão localizados importantes reservatórios de usinas hidrelétricas, como Paraibuna, Santa Branca e Funil.

Por estar localizada entre os maiores polos industriais e populacionais do País, a bacia hidrográfica do rio Paraíba do Sul tem um importante papel. Além disso, se destaca também pelos acentuados conflitos de usos múltiplos da água e pelo peculiar desvio das águas para a bacia hidrográfica do rio Guandu, com a finalidade de gerar energia e abastecer a população da Região Metropolitana do Rio de Janeiro. Forma-se, assim, o Sistema Hidráulico do rio Paraíba do Sul - um complexo conjunto de estruturas hidráulicas existentes nas bacias hidrográficas dos rios Paraíba do Sul e do Guandu, que interliga as duas bacias.

Os principais usos da água são: abastecimento (14,2 milhões de pessoas abastecidas), irrigação, geração de energia hidrelétrica e diluição de esgotos. Esse último uso é uma das principais fontes de poluição do rio Paraíba do Sul, que apresenta estado de degradação preocupante, especialmente nos trechos que cruzam ou tangenciam áreas urbanas." Conferir em: 〈https://www.ana.gov.br/sala-de-situacao/paraiba-do-sul/paraiba-do-sul-saiba-mais〉.

${ }^{5}$ Ver mapa detalhado da divisão regional das bacias hidrográficas do Estado do Rio de Janeiro elaborado pelo Instituto Estadual do Ambiente (INEA) <http://www.inea.rj.gov.br/cs/groups/public/@inter_digat_geagua/documents/document/zwew/mtm1/ edisp/ine a0135675.pdf $>$.
} 


\section{Figura 1. Regiões Hidrográficas do Estado do Rio de Janeiro}

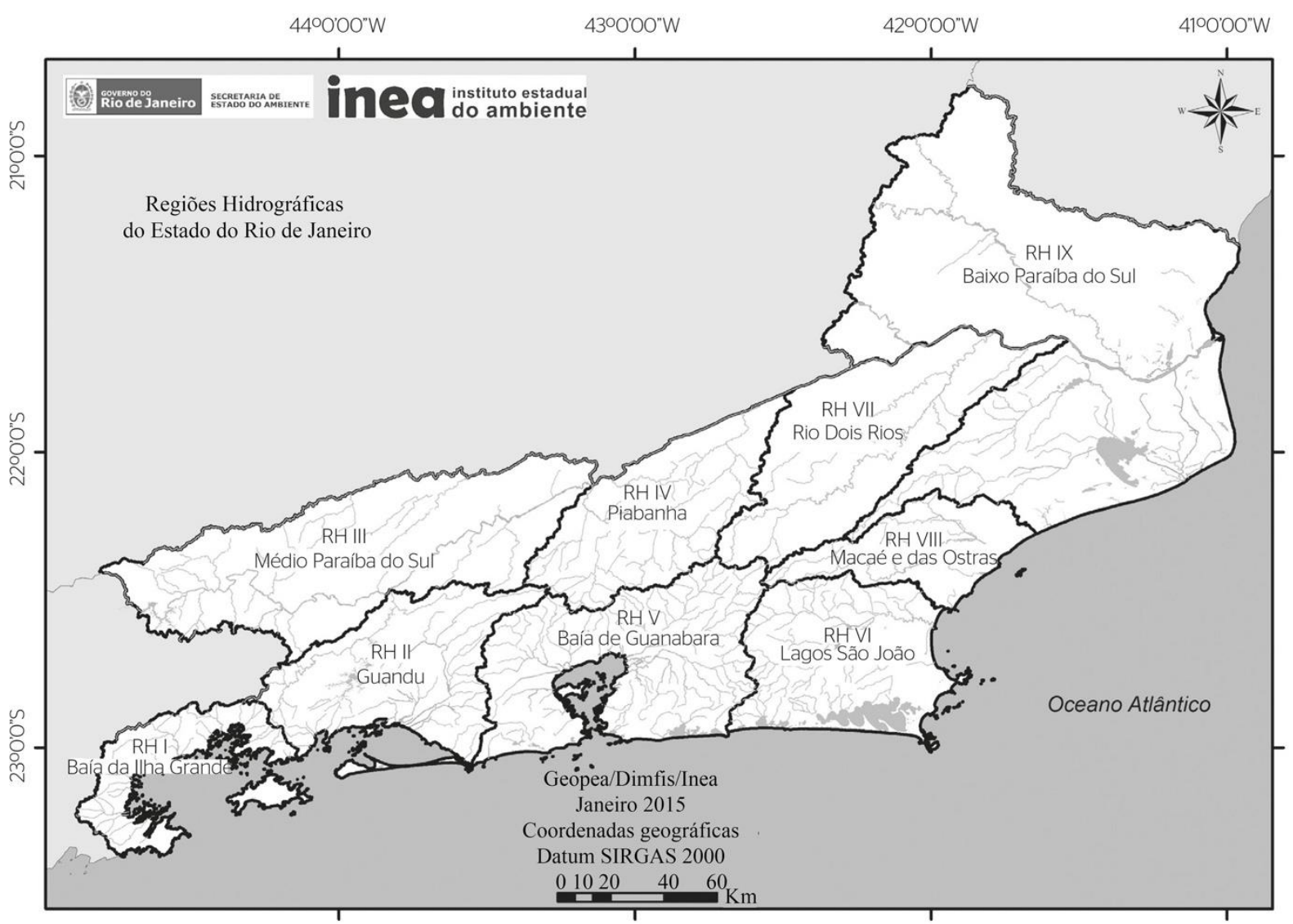

Fonte: Conselho Estadual de Recursos Hídricos do Estado do Rio de Janeiro (CERHI-RJ), 2015.

A metodologia desse trabalho se fundamentou em diferentes fontes de pesquisas e em levantamentos realizados sobre: 1. Legislação e documentos oficiais do governo e de empresas vinculadas ao fornecimento, à distribuição e à provisão hidrossocial na Região Metropolitana do Rio de Janeiro ${ }^{6} ; 2$. Dados sobre condições meteorológicas e pluviosidade obtidos do Instituto Nacional de Meteorologia (INMET), do Instituto Nacional de Pesquisas Espaciais (INPE) e do Sistema Alerta Rio da Prefeitura do Rio de Janeiro - Alerta Rio ${ }^{7}$; 3. Números relativos ao desmatamento da Mata Atlântica do Instituto Estadual do Ambiente (INEA) ${ }^{8}$ e ao Atlas dos Remanescentes Florestais da Mata Atlântica (SOSMA) ${ }^{9}$; 4. Dados e registros da população no município do Rio de Janeiro do Instituto Brasileiro de Geografia e Estatística (IBGE) ${ }^{10} ; 5$. Dados sobre captação, vazão e consumo per capita de água da $\operatorname{CEDAE}^{11}$; 6. Relatórios e Planos Estratégicos da Bacia Hidrográfica do Guandu, desenvolvidos pelo Comitê da Bacia

\footnotetext{
${ }^{6}$ INEA 2019 <http://www.inea.rj.gov.br/wp-content/uploads/2019/03/baseLegal_4aedicao_INTERATIVO.pdf $>$.

${ }^{7}$ Conferir em: a) INMET <https://portal.inmet.gov.br/>; b) INPE/CPTEC <https://www.cptec.inpe.br/rj/rio-dejaneiro>; c) Alerta Rio <http://www.sistema-alerta-rio.com.br/dados-meteorologicos/download/dadosmeteorologicos/>.

${ }^{8}$ INEA MAPS

<https://inea.maps.arcgis.com/apps/MapSeries/index.html?appid=2a8b5c83f8f94676b1aaa13f601218fd >.

${ }^{9}$ SOSMA 2019 <https://www.sosma.org.br/wp-content/uploads/2019/05/Atlas-mata-atlantica_17-18.pdf >.

${ }^{10}$ IBGE: <https://www.ibge.gov.br/cidades-e-estados/rj.html>.

${ }^{11}$ INEA 2018 <http://www.inea.rj.gov.br/wp-content/uploads/2019/01/Livro_Atlas-dos-Mananciais-deAbastecimento-do-Estado-do-Rio-de-Janeiro.pdf $>$.
} 
Hidrográfica do Guandu ${ }^{12}$ e pela Associação Pró-Gestão das Águas da Bacia Hidrográfica do Rio Paraíba do Sul (AGEVAP) ${ }^{13}$; 7. Livro sobre o Colapso Hídrico, organizado pela Comissão Especial da Câmara Municipal do Rio de Janeiro, presidida pelo Partido Socialismo e Liberdade $(\mathrm{PSOL})^{14} ; 8$. Outras pesquisas realizadas pela Federação das Indústrias do Rio de Janeiro FIRJAN, pelas Universidade Federal do Rio de Janeiro (UFRJ), Universidade do Estado Rio de Janeiro (UERJ), pela Fundação SOS Mata Atlântica, pelo Painel Intergovernamental de Mudanças Climáticas (IPCC) e pela Agência Nacional de Águas (ANA).

Esses levantamentos evidenciaram a complexa situação de insegurança hídrica da Região Metropolitana do Rio de Janeiro que se relaciona ao ciclo da água e se vincula aos mecanismos de uso, controle, fornecimento e da distribuição de água que nos ajudaram a compreender como e porque o município do Rio de Janeiro e a Região Metropolitana do Rio de Janeiro (RMRJ) continuam passando por uma escassez hídrica.

Estudo realizado pela Fundação Joaquim Nabuco ${ }^{15}$ aponta que um colapso total na provisão do sistema hídrico na RMRJ está eminente para as próximas décadas, devido à redução de investimentos e de recursos do Fundo Estadual de Conservação Ambiental (FECAM) que contribuíram também para essa tendência. Nos últimos 15 anos, a FECAM perdeu, por desvio de função de receitas, um valor total estimado em cerca de $\mathrm{R} \$ 10.800 .000,00$ (10 bilhões e 800 milhões de reais); por isso, é necessário enfrentar o colapso hídrico do Rio de Janeiro com ações políticas, planejamento e estratégias de gestão, pois a RMRJ possui problemas históricos de abastecimento, principalmente, nas suas zonas periféricas e um colapso que pode deixar uma população de mais de 13 milhões sem acesso à água potável.

Diante desse contexto, é importante que estratégias, práticas e tecnologias capazes de coletar, armazenar, tratar e distribuir a água como recurso sejam oferecidas às populações e às regiões urbanas que enfrentem tais problemas.

Dentro dessa perspectiva, a partir da análise referente à dimensão hídrica Região Metropolitana do Rio de Janeiro, indicaremos um quadro de ações políticas e estratégias potencialmente mitigadoras para enfrentar o processo de escassez.

Assim, além da escassez, os temas norteadores desta pesquisa foram o abastecimento público, as crises hídricas, os conflitos de uso, as mudanças climáticas e as influências das políticaseconômicas neoliberais, que pretendem privatizar e reduzir a participação do estado na prestação dos serviços de consumo coletivo ou social ${ }^{16}$.

\footnotetext{
12 Tubbs Filho et al 2012 <http://www.inea.rj.gov.br/wp-content/uploads/2019/01/Livro_BaciaHidrogr\%C3\%A1 fica-dos-Rios-Guandu-da-Guarda-e-Guandu-Mirim.pdf $>$.

${ }^{13}$ AGEVAP 2017 <http://sigaceivap.org.br:8080/publicacoesArquivos/guandu/arq_pubMidia_Processo_0632013_P2TOMOII.pdf $>$.

${ }^{14}$ Ver o livro elaborado pelo Presidente da Comissão, Vereador Renato Cinco do Partido Socialismo e Liberdade "Crise Hídrica em Debate" <https://www.researchgate.net/publication/317673072>.

${ }^{15}$ Conferir o artigo publicado no site da Fundação Joaquim Nabuco "Risco de colapso hídrico no Rio de Janeiro" $<$ https://www.fundaj.gov.br/index.php/documentarios-e-estudos-sobre-as-secas/11706-risco-de-colapso-hidricono-rio-de-janeiro>.

${ }^{16}$ Capel $2000<$ http://www.ub.edu/geocrit/b3w-218.htm>.
} 


\section{Formas e características da escassez hídrica na Região Metropolitana do Rio de Janeiro, no período atual}

A escassez hidrossocial ${ }^{17}$ no período atual tende a se manifestar de duas formas: a primeira em relação à quantidade de água e, a segunda, em relação à sua qualidade. As causas do aumento da escassez quantitativa da água são decorrentes da expansão do desmatamento das Matas Atlântica e ciliares no Estado do Rio de Janeiro, que influencia na diminuição da capacidade de retenção da água pelos solos e na redução dos índices pluviométricos e fluviométricos, resultantes de ações provocadas por mudanças climáticas; mas é possível constatar também outros fatores que influenciam nessa escassez hídrica, como: a distribuição desigual da oferta de água entre as zonas urbanas principalmente no Município do Rio de Janeiro; as perdas e o desperdício na rede de distribuição da água; o uso acentuado e desigual da água para a produção de energia elétrica ${ }^{18}$ por diferentes agentes privados vinculados ao setor industrial, principalmente nas regiões hidrográficas RH II e RH III (Figura 2).

\section{Figura 2. Demandas e balanço hídrico setorial}

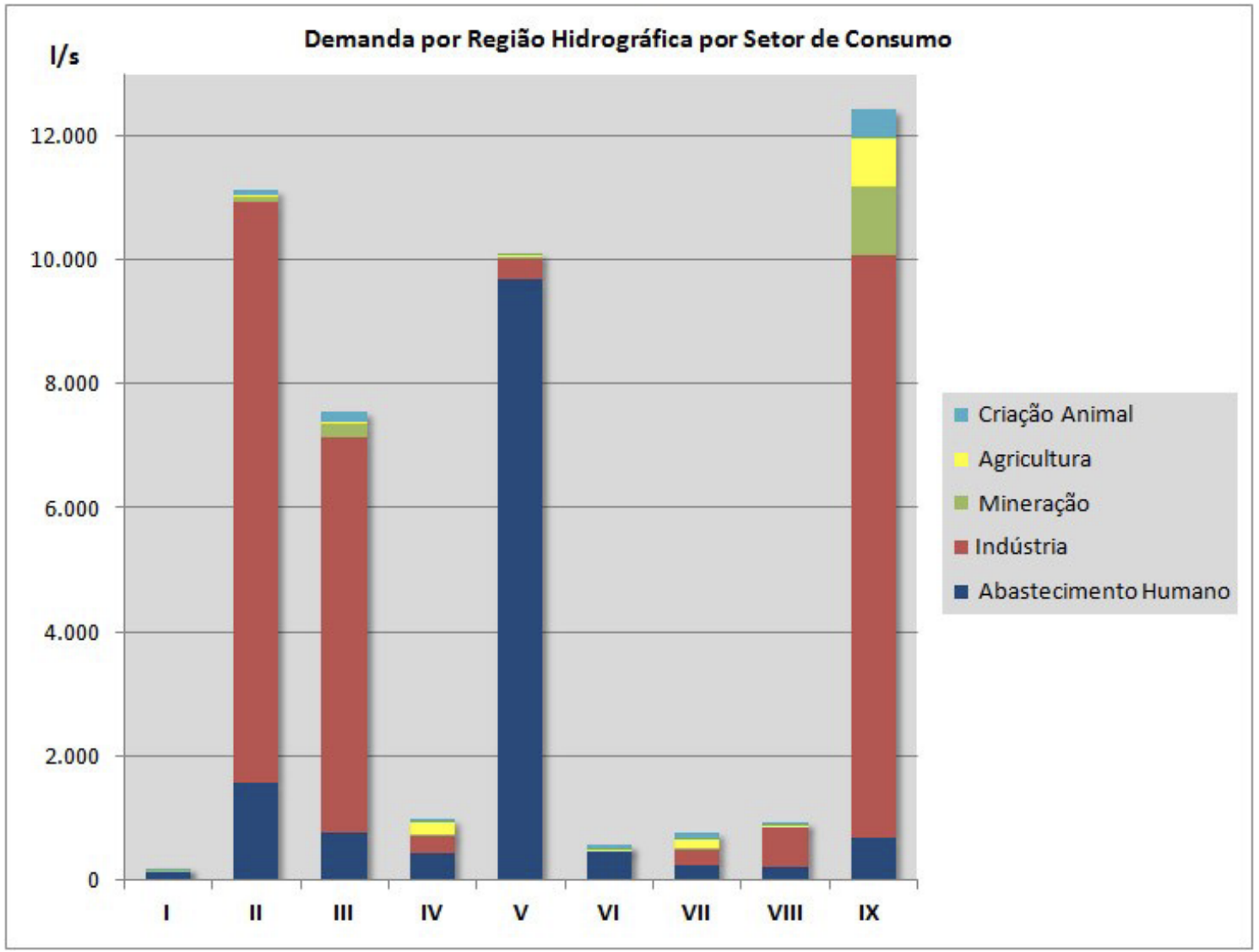

Fonte: Plano Estadual de Recursos Hídricos do Estado do Rio de Janeiro (PERHI - RJ) 2014, p.82.

\footnotetext{
${ }^{17}$ Britto et al 2016 <https://www.scielo.br/pdf/asoc/v19n1/pt_1809-4422-asoc-19-01-00183.pdf>.

${ }^{18}$ Lameira 2010, conferir Tabela 4, p.30:

<https://www.infoteca.cnptia.embrapa.br/bitstream/doc/881979/4/documentos122.pdf>.
} 
Por sua vez, as causas da escassez qualitativa da água, sob a gestão Companhia Estadual de Águas e Esgotos do Rio de Janeiro, são resultantes majoritariamente da poluição na rede de abastecimento e da contaminação dos mananciais da rede hídrica por esgoto, resíduos industriais e agrotóxicos, o que torna o fornecimento de água para consumo, além de custoso, precário à maioria da população residente na Região Metropolitana do Rio de Janeiro (RMRJ), impróprio para a população das áreas periféricas ou mais pobres do território fluminense.

Além dos fatores que contribuem para a contaminação e a poluição da rede hídrica estadual, há problemas relacionados predominantemente à gestão política dos recursos hídricos, que contribuem para a má distribuição e para o baixo volume de água ofertado para o consumo social, o que explica, de certo modo, a abundância e a maior oferta de água para os setores industriais e comerciais privados, e a escassez ou a menor oferta de água para o abastecimento público da maioria da população fluminense.

Portanto, no Estado do Rio de Janeiro, os elementos causadores da escassez hídrica apresentam quatro características indissociáveis: a primeira, a físico-ambiental, oriunda da dinâmica de retenção da água dos solos ou do balanço frequência de chuvas nas regiões próximas à bacias hidrográfica do Rio Paraíba do Sul e do Rio Guandu; a segunda, a social, geradora do desmatamento da vegetação ribeirinhas ou matas ciliares, da poluição e da contaminação hídrica; a terceira, a socioambiental, vinculada às questões das formas capitalistas de apropriação, transformação e destruição da natureza, que interferem na qualidade e nos custos da distribuição dos recursos hídricos; a quarta, a política, advinda do poder concedente do estado que por meio da gestão e do planejamento do sistema hídrico, que privilegia mais o interesse privado do que o público e gerencia de forma inadequada os recursos de domínio público, gerando desperdícios e perdas de recursos para população.

Nesse sentido, qualquer análise a ser realizada sobre o processo de escassez hídrica no município do Rio de Janeiro não poderá prescindir da investigação das características desses elementos causadores ou determinantes.

\section{A escassez como exacerbação das desigualdades na Região Metropolitana do Rio de Janeiro}

Em 28 de Julho de 2010, conforme resolução da Assembleia Geral da Nações Unidas, o acesso à água potável e ao saneamento básico passaram a ser considerados como um direito humano fundamental ${ }^{19}$, e o contexto atual de crise sanitária e disseminação da COVID-19 deixou ainda mais evidente porque o acesso à água é um direito fundamental.

A redução no regime de chuvas ou estiagem entre os anos $2013 / 2015^{20}$, que praticamente reduziu o nível nos reservatórios de água da Região Sudeste, tornou evidente o risco de 35 milhões de habitantes das regiões metropolitanas do Rio de Janeiro e de São Paulo ficarem sem água potável e fornecimento de energia elétrica.

Esta estiagem correspondeu, sobretudo na Bacia do Paraíba do Sul, a pior dos últimos 85 anos. Este fato afetou o abastecimento hídrico da Região Metropolitana do Rio de Janeiro. Estudos

\footnotetext{
${ }^{19}$ Ver documento da ONU “Água potável: direito humano fundamental” <https://nacoesunidas.org/agua-potaveldireito-humano-fundamental/>.

20 Buckeridge e Ribeiro 2018, p.17 <http://www.iea.usp.br/publicacoes/ebooks/livro-branco-daagua/at_download/file>; $\quad$ Empinotti, Jacobi e $\quad$ Fracalanza $2016, \quad$ p. 70 <https://www.revistas.usp.br/eav/article/view/124267/120590>.
} 
recentes revelaram que os anos de 2016 e 2020 foram os mais quentes já registrados desde que começaram as medições em 1880, de acordo com a série histórica informada pela Administração Nacional do Espaço da Aeronáutica (NASA) e a Agência Nacional Oceânica e Atmosférica dos Estados Unidos (NOAA) ${ }^{21}$.

Em 2011, o consumo de água era de 189 litros per capita por dia no Estado do Rio de Janeiro ${ }^{22}$, no entanto, em alguns munícipios da região metropolitana, o acesso à água continuava sendo realizado de forma irregular ou intermitente e, por isso, uma parcela dos moradores recebia água apenas de 3 a 4 dias por semana ${ }^{23}$.

No período atual, a população da Região Metropolitana do Rio de Janeiro tem se tornado refém do modelo de gestão de distribuição de água da Bacia Hidrográfica dos Rio Guandu, Guandu Mirim e Guarda ${ }^{24}$.

O ponto de partida para compreensão do fenômeno da escassez passa pela transparência (Lei Federal $\left.n^{\circ} 9.433 / 1997\right)^{25}$ e pela consciência ${ }^{26}$ da condição social da exclusão. Por que alguns são "possuidores" e outros são "excluídos" do acesso à água potável? Essa consciência fundamenta o entendimento de que a escassez não é fruto do acaso ou um acontecimento natural produzido pelas forças da natureza, ela é uma produção social e, como tal, exacerba as desigualdades e amplia o sistema de apartação social, no qual uns são os possuidores e outros são os não possuidores ${ }^{27}$ daquilo que deveria ser pela lei de domínio público, a água.

\section{Funcionamento das redes técnicas de abastecimento público de água da Região Metropolitana do Rio de Janeiro}

O problema do abastecimento da água e da escassez hídrica do Rio de Janeiro não é algo recente e tem origem na fundação da cidade, em meados do século $\mathrm{XVI}^{28}$. A principal fonte de suprimento de água nesta época era o Rio Carioca.

Até o início do século XVIII a provisão e o abastecimento da água eram realizados de forma rudimentar por índios, escravos negros e posteriormente por aguadeiros, vendedores d'água que transportavam a água em barris e bilhas de barro.

O crescimento populacional e a utilização da água na produção agrícola agravaram a questão do abastecimento de água, esses dois fatores acarretaram a carestia da água, o que desencadeou uma longa luta pelo seu uso comum ${ }^{29}$. A gestão desse impasse aconteceu no final do século

\footnotetext{
${ }^{21}$ Sobre o conteúdo relativo ao aquecimento atmosférico no período atual, ler o artigo de Zaar 2021 <https://doi.org/10.1344/ara2021.250.33232>. Informação também disponível em $<$ https://www.researchgate.net/publication/317673072>.

${ }^{22}$ Marques 2018, p.148.

${ }^{23}$ Britto et al, 2016, p. 3.

${ }^{24}$ Pinto 2010, p. 93

<http://www.dominiopublico.gov.br/pesquisa/DetalheObraForm.do?select_action=\&co_obra=180481 >

${ }^{25}$ Empinotti, Jacobi e Fracalanza 2016, p. 65 <https://www.revistas.usp.br/eav/article/view/124267/120590>.

${ }^{26}$ Santos 2000, p. 129.

${ }^{27}$ Santos 2000, p. 129-130.

${ }_{28}$ Abreu 1992, p.56.

${ }^{29}$ Abreu 1992, p.57.
} 
XVIII, com a construção de aquedutos e com o desenvolvimento, no final do século XIX, de obras de captação e de distribuição de água para o abastecimento da cidade do Rio de Janeiro ${ }^{30}$.

No período atual, o abastecimento de água na RMRJ é garantido por quatro sistemas hídricos principais de captação: Acari, Ribeirão das Lajes, Guandu e Imunana-Laranjal (Figura 3).

Figura 3. Abastecimento de Água na Região Metropolitana do Rio de Janeiro

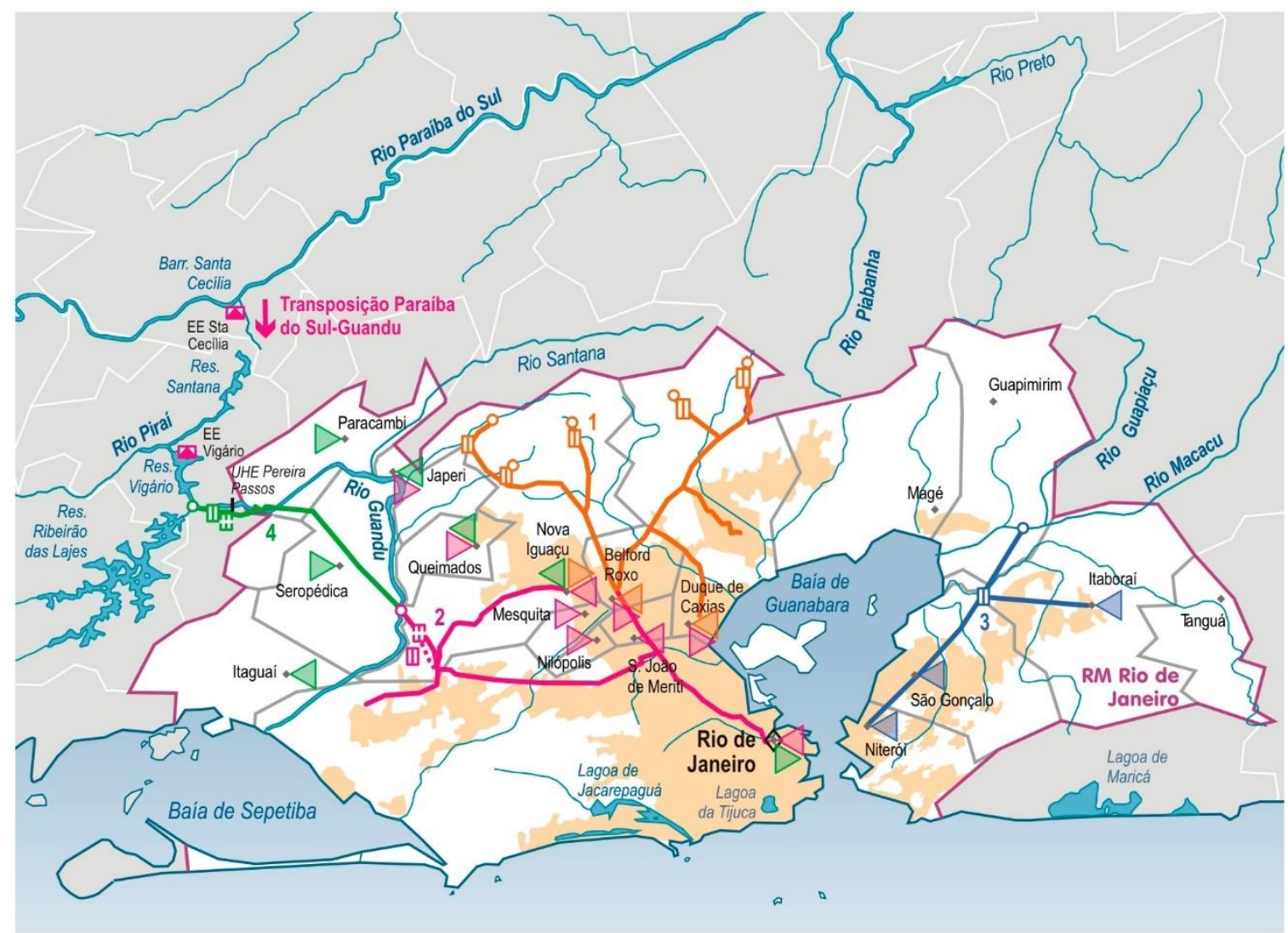

Sistemas Interligados

1 SIN Acari

2 SIN Guandu

3 SIN Imunana-Laranjal

4 SIN Ribeirão das Lajes

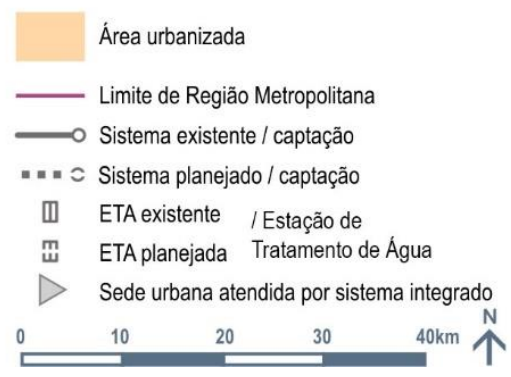

Fonte: Agência Nacional de Águas - ANA, 2010.

$<$ http://atlas.ana.gov.br/atlas/forms/analise/RegiaoMetropolitana.aspx ?rme=18>.

${ }^{30}$ Abreu 1992, p.82. 
O complexo de Ribeirão das Lajes, onde foi instalada a Light ${ }^{31}$, -considerada no início do século $\mathrm{XX}$, a maior hidrelétrica do mundo-, possui adutoras que passam pelos municípios de Seropédica, Queimados e se integram, posteriormente, a Nova Iguaçu e Itaguaí ${ }^{32}$, chegam também ao reservatório de Pedregulho ${ }^{33}$, criado em 1880, no município do Rio de Janeiro. Essas adutoras do sistema Ribeirão das Lajes se interligam $8 \mathrm{~km}$ após a Estação de Tratamento de Água do Rio Guandu (ETA Guandu), formando o sistema Guandu.

O sistema hídrico Guandu, com a ETA Guandu, é responsável pelo abastecimento de mais de 9 milhões de pessoas, incluindo o município do Rio de Janeiro.

Inaugurada em 1955, a ETA Guandu representa uma extraordinária obra de engenharia originária da transposição das águas do Rio Paraíba do Sul, que abastece a Baixada Fluminense da Região Metropolitana do Rio de Janeiro (Nilópolis, Nova Iguaçu, Duque de Caxias, Belford Roxo, São João de Meriti, Itaguaí e Queimados) e 151 bairros da cidade do Rio de Janeiro, por meio de dois subsistemas: Marapicú e Lameirão ${ }^{34}$.

Outro sistema hídrico de captação mais antigo e menos volumoso é o Guandu/Lajes/Acari, que possui diferentes pontos de captação, suas águas se misturam às águas distribuídas pela ETA Guandu, passando a integrar o sistema de abastecimento e captação de água da Baixada Fluminense ${ }^{35}$.

Assim, embora haja um volume excepcional de água produzida pelo sistema Guandu, existe uma parcela considerável da população de baixo poder econômico ainda sem acesso às redes de abastecimento, principalmente nas áreas de periferia e nas favelas do município do Rio de Janeiro, enquanto as regiões mais abastadas da cidade recebem mais água e possuem um acesso aos serviços de domínio público mais regular.

A questão urbana central do abastecimento de água é o atendimento às demandas vinculadas aos múltiplos usos da água pelos agentes privados e públicos na Região Metropolitana do Rio de Janeiro. No entanto, o crescimento das populações urbanas dos municípios da Baixada Fluminense e da Zona Oeste da capital do estado coloca uma necessidade precípua aos gestores públicos: lutar para garantir a prioridade do abastecimento público, uma vez que a população de baixa renda de algumas áreas da Região Metropolitana do Rio de Janeiro, mesmo estando

\footnotetext{
${ }^{31}$ Sobre a história da Light no Brasil ler o livro de Duncan Mcdowall Light: a história da empresa que modernizou o Brasil 2008.

${ }^{32}$ Segundo Britto et al 2016, p. 194: “As adutoras transportam a vazão total de 5.500 1/s abastecendo parte dos municípios de Paracambi (104,50 1/s), Seropédica (319 1/s), Queimados (44 1/s), Japeri (154 1/s), Nova Iguaçu $(38,50$ 1/s), Rio de Janeiro (4.510 1/s) e Itaguaí (330 1/s)".

${ }^{33}$ Ver Britto et al 2016, p. 194: “As adutoras que partem de Lajes passam por Seropédica e Nova Iguaçu e chegam ao reservatório do Pedregulho, em Benfica, no município do Rio de Janeiro."

${ }^{34}$ De acordo com Britto et al 2016, p. 194: "Do subsistema Marapicú, a água é bombeada através de seis adutoras, aduzindo água para a Zona Oeste e a Zona Norte da cidade do Rio de Janeiro e para a Baixada Fluminense. Esta última recebe uma vazão máxima de 15.100 1/s provenientes das adutoras da Baixada, por interligações entre os subsistemas e o sistema Acari. Já do subsistema Lameirão a água é aduzida através de vários sistemas de transposição, abastecendo em marcha, ao longo dos seus $33 \mathrm{~km}$, vários bairros da Zona Oeste, Zona Norte, Centro e Zona Sul da Cidade do Rio de Janeiro, além do município de Nilópolis na Baixada Fluminense."

${ }^{35}$ Segundo o relatório gerencial PERHI-RJ 2014, p.31: “O sistema Guandu/Lajes/Acari abastece a maior parte da Região Metropolitana, atendendo a uma população da ordem de 8,6 milhões de habitantes de Belford Roxo, Duque de Caxias, Japeri, Mesquita, Nilópolis, Nova Iguaçu, Queimados, Rio de Janeiro e São João de Meriti. Para atender à população projetada para 2030, o Sistema Guandu/Lajes/Acari necessita ampliar a produção de água em 18.000 1/s. O único manancial viável para essa ampliação é o rio Guandu. Com a implantação de um rigoroso programa de redução de perdas, a necessidade de ampliação do sistema poderá ser reduzida para 12.000 1/s."
} 
localizadas geograficamente próximas à ETA Guandu, Santa Cruz e vários bairros da Zona Oeste, na periferia, sofrem com a falta frequente de água ${ }^{36}$.

Além da ausência de rede de abastecimento, existem problemas com relação à quantidade, qualidade e frequência do fornecimento de água em toda a região abastecida pelo sistema Guandu, causando limitações ao acesso à água para maioria dessa população de baixa renda da Região Metropolitana do Rio de Janeiro ${ }^{37}$.

\section{Abastecimento público, qualidade da água da Bacia Hidrográfica Guandu e as crises hídricas no período atual}

Em 2001, a escassez de água nos reservatórios das hidrelétricas que abastecem os principais centros urbanos brasileiros, ocasionou grandes apagões e conduziu à adoção de políticas de racionamento no fornecimento de água e energia elétrica ${ }^{38}$, como a elevação das taxas de cobrança, com a intenção de racionalizar o uso da água.

Nesse mesmo período, a região hidrográfica da baía de Sepetiba passou por um processo de reestruturação produtiva, impulsionada pelo desenvolvimento econômico, direcionado pelas demandas do mercado internacional de commodities, realizadas sob influência de expansão do porto de Itaguaí. Nessa região, dois setores industriais se destacaram, o referente à logística portuária e o vinculado à siderurgia. A entrada em operação da Companhia Siderúrgica do Atlântico (CSA), da ThyssenKrupp, da Vale, a ampliação da Cosigua/Gerdau e o crescimento da atuação da Companhia Siderúrgica Nacional (CSN) em Itaguaí passaram a constituir a consolidação de um novo arranjo produtivo, que gerou um conjunto de novas demandas por recursos hídricos da Bacia Hidrográfica do Guandu até a Baía de Sepetiba ${ }^{39}$.

O processo de industrialização nas zonas periféricas da Região Metropolitana do Rio de Janeiro reforçou a dinamização e requalificação da metrópole e, devido a isso, as grandes corporações passaram a influir mais intensamente nas tomadas de decisões e na agenda de investimentos locais ${ }^{40}$. Essa reestruturação econômica do estado do Rio de Janeiro, a partir de setores industriais, como petroquímica e siderurgia, que são grandes consumidores de água, ocasionaram a contaminação dos rios da região por esgoto e efluentes industriais, assim como a demanda por captação de água potável, enquanto a vazão do Rio Guandu tem continuado sem alteração, o que tem contribuído para agravar tensões e conflitos pelo consumo dos recursos hídricos ${ }^{41}$.

Em 2003, iniciou-se outra grave crise na Região Sudeste devido à estiagem e, por isso, os reservatórios das grandes empresas de abastecimento de São Paulo alcançaram o nível de 5\% de sua capacidade, muito próximo do nível crítico, o que novamente passou a exigir a adoção de políticas de racionamento. A cidade do Rio de Janeiro sofreu, com menos intensidade, os efeitos dessa estiagem.

\footnotetext{
${ }^{36}$ Dias e Dieile da Silva 2016, p.100.

${ }^{37}$ Cinco 2016, p. 30.

${ }^{38}$ Fearnside 2015, p. 1-3 <http://philip.inpa.gov.br/publ_restritas/2015/Rios_voadoresS\%C3\%A9rie_completa.pdf $>$.

${ }^{39}$ Gusmão 2010, p. 25.

${ }^{40}$ Gusmão 2010, p. 28.

${ }^{41}$ Castro e Ferreirinha 2012, p. 73 <http://www.ppegeo.igc.usp.br/index.php/anigeo/article/view/5953>.
} 
Em 2007, a Companhia Estadual de Águas e Esgotos do Rio de Janeiro, considerada no Livro dos Recordes como a companhia com a maior estação de tratamento de água do mundo em produção contínua ${ }^{42}$, mesmo sem atender à toda demanda da Região Metropolitana do Rio de Janeiro, confirmou que aumentaria em cerca de $30 \%$ sua capacidade, para ampliar a prestação de suas atividades operacionais no sistema da bacia hidrográfica do Guandu. Essas obras seriam realizadas com recursos do antigo Programa de Aceleração do Crescimento (PAC), aprovados pelo Governo Federal ${ }^{43}$. Esta decisão técnica foi tomada após as consequências das crises hídricas de 2001 e 2003 no sistema Guandu e os problemas decorrentes da crise de abastecimento, isso até a chegada da nova crise hídrica iniciada no ano de 2013, que perdurou até o final de 2015.

Essa crise hídrica produziu alterações no volume hídrico destinado ao abastecimento público prestado pela Companhia Estadual de Águas e Esgotos do Rio de Janeiro e houve também alterações na frequência de abastecimento de algumas áreas residenciais, embora os setores energético e industrial não tenham tido o volume de captação de água reduzido para suas atividades produtivas, fato que demonstra duas contradições de acordo com o que dispõe a lei das águas, Lei $\mathrm{n}^{\circ} 9.433^{44}$, cujo Art.15 - outorga de direito de uso de recursos hídricos poderá ser suspensa ... nas seguintes circunstâncias: "Inciso - III. necessidade premente de água para atender a situações de calamidade, inclusive as decorrentes de condições climáticas adversas; Inciso - V. necessidade de se atender a usos prioritários, de interesse coletivo, para os quais não se disponha de fontes alternativas ${ }^{45}$.

Como é possível constatar pela descrição anterior, existem conflitos de uso pela água no Guandu, que vão desde a transposição do Paraíba do Sul, entre os setores elétrico, industrial, abastecimento público e pesca artesanal, até a foz do Guandu no Canal de São Francisco ${ }^{46}$.

Quando o Rio Guandu chega à níveis críticos de vazão baixa, devido a reduções de volume de água transposta oriunda do Paraíba do Sul, a interferência da demanda industrial entra em conflito direto com o abastecimento público. Esta situação ocorreu durante a crise hídrica mencionada entre os períodos de 2013 e 2015, onde a captação de água pela Companhia Estadual de Águas e Esgotos do Rio de Janeiro sofreu uma redução de $20 \mathrm{~m} 3 / \mathrm{s}$, enquanto o setor industrial do complexo localizado na Baía de Sepetiba não sofreu diminuição no seu consumo.

No ano de 2013, segundo dados fornecidos pelo Comitê das Bacias Hidrográficas dos rios Guandu, da Guarda e Guarda-Mirim, existiam duzentos e quatro indústrias situadas nessas áreas

\footnotetext{
${ }^{42}$ Crise Hídrica em debate 2016.

${ }^{43}$ Conferir em Guandu 2017, p. 9. “Além de uma nova estação de tratamento serão construídos canais desarenadores, reservatórios, elevatórias de água bruta e tratada e adutoras que se interligarão com o sistema atual, conferindo maior segurança operacional e flexibilidade para o sistema de abastecimento do Grande Rio e principalmente da Baixada Fluminense. As estruturas da antiga captação serão aproveitadas, pois têm capacidade de aduzir um volume suficiente para a ETA existente e o Novo Guandu, o que facilitará a execução da obra e diminuirá os custos da ampliação. Outra obra importante será o desvio das águas dos rios Poços, Queimados e Ipiranga. Essas águas - muito poluídas, deságuam no rio Guandu, junto à captação da CEDAE. Com o desvio dessa poluição, a CEDAE aumentará a segurança do Sistema, melhorando a qualidade da água captada e diminuindo o custo do tratamento, já que reduzirá o consumo de produtos químicos".

${ }^{44}$ Cf. Lei $\mathrm{n}^{\circ}$ 9.433, de 8 de janeiro de 1997 <http://www.planalto.gov.br/ccivil_03/LEIS/L9433.htm>.

${ }^{45}$ Carneiro 2016, p. 40.

46 Segundo Cinco 2016, p 29: “existe um claro conflito pela água do Paraíba do Sul entre o setor elétrico (que precisa fazer uso dos reservatórios para geração de energia), o setor industrial (que usa água nos processos produtivos), o abastecimento público e pescadores da foz do Guandu (Canal de São Francisco)".
} 
e seus arredores, que receberam outorgas de funcionamento do Instituto Estadual do Ambiente e da Agência Nacional de Águas ${ }^{47}$.

Nos últimos meses de 2015, houve o indício de uma lenta recuperação dos reservatórios devido ao novembro mais chuvoso em $37 \operatorname{anos}^{48}$. Dentre os distintos reservatórios abastecidos pelas águas do Rio Paraíba do Sul, o que apresentou melhor recuperação, de acordo com os dados do boletim de monitoramento da bacia do Paraíba do Sul, foi Funil, que chegou a 39\% do seu volume útil.

Importante destacar que mesmo assim, os resultados apresentados pela Comissão Especial Sobre Colapso Hídrico da Câmara Municipal do Rio de Janeiro mostraram que pode existir "um déficit de vazão, se todos os empreendimentos utilizarem a água doce do Rio Guandu ao mesmo tempo"49.

Após três graves crises hídricas, ocorridas nas primeiras décadas do século XXI, a Companhia Estadual de Águas e Esgotos do Rio de Janeiro anunciou o andamento do projeto de ampliação que iniciou as operações para implementação "com um investimento de 3,4 bilhões de reais"

No entanto, a ampliação do sistema não foi finalizada até meados de 2020; por isso, no início de 2021, ocorreu uma nova crise hídrica enfrentada pela população da Região Metropolitana do Rio de Janeiro.

Toda população dos municípios da Região Metropolitana do Rio de Janeiro localizados à oeste da Baía de Guanabara, resguardadas as devidas proporções e intensidades, foi afetada pela nítida perda de qualidade da água fornecida pela Companhia Estadual de Águas e Esgotos do Rio de Janeiro. A água que abastece grande parte desta região metropolitana tem chegado aos domicílios turva, com odor, cor e gosto alterados ${ }^{51}$, a causa pode estar relacionada ao excesso de esgotos lançados pelos rios afluentes (1 - Rios Poços/Queimados e 2- Cabuçu/Ipiranga) à Bacia Hidrográfica do Rio Guandu ${ }^{52}$ (Figura 4).

\footnotetext{
${ }^{47}$ Consultar o Plano de Contingência para Abastecimento de Água (Guandu), Produto P6 - Volume II: Diagnóstico das Áreas Estudadas, elaborado pelo Comitê das Bacias Hidrográficas dos Rios Guandu, da Guarda e GuardaMirim, 2015, p. $128-133$ <http://sigaceivap.org.br:8080/publicacoesArquivos/guandu/arq_pubMidia_Produto06_Volume_2.pdf>.

${ }^{48}$ Cinco 2016, p. 31.

49 Tubbs Filho et al 2012, p. 113.

${ }^{50}$ Notícia disponibilizada, em 09/03/2020, pelo portal Tratamento de Água "CEDAE está implantando na Baixada Fluminense/RJ o maior projeto de abastecimento de água de todo o Brasil" <https://www.tratamentodeagua.com.br/cedae-abastecimento-agua-brasil/>.

51 Disponível em: <https://www.nexojornal.com.br/expresso/2020/01/28/Quais-as-dimens\%C3\%B5espol\%C3\%ADticas-da-crise-h\%C3\%ADdrica-do-Rio $>$

${ }^{52}$ Conferir reportagem do RJTV da Rede Globo, de 03 de fevereiro de 2020: "Afluentes do rio Guandu carregam poluição para a bacia”: Disponível em: 〈https://globoplay.globo.com/v/8291499/>
} 
Figura 4. Afluentes da Bacia Hidrográfica do Rio Guandu

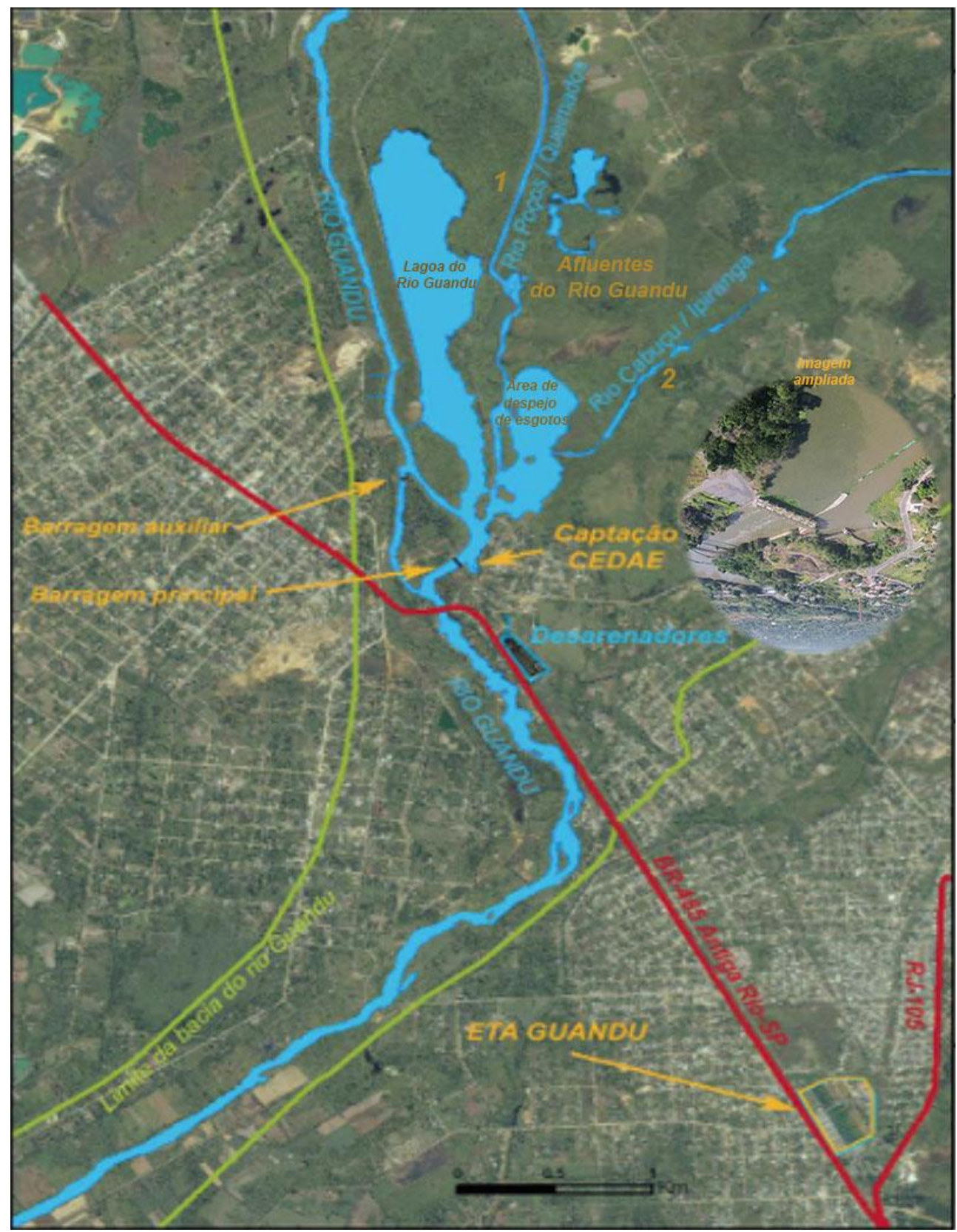

Fonte: Relatório de Impacto Ambiental - RIMA. Rio de Janeiro: 2011. <http://www.ceivap.org.br/downloads2011/CEDAE_RIMA.pdf>

Oitenta e seis bairros na capital e seis municípios da Região Metropolitana do Rio de Janeiro relataram problemas. Apenas os municípios de Itaboraí, São Gonçalo e Niterói, que são abastecidos pelo sistema Imunana/Laranjal ${ }^{53}$, não os apresentaram. Mas, de acordo com a

\footnotetext{
${ }^{53}$ Segundo o relatório gerencial PERHI-RJ, 2014, p.32: "O sistema Imunana/Laranjal abastece uma população da ordem de 1,5 milhão de habitantes de Niterói, São Gonçalo, Itaboraí e Ilha de Paquetá (do município do Rio de Janeiro). A captação é no canal de Imunana, formado pelos rios Macacu e Guapiaçu (na RH V). O sistema produz 5.500 1/s e já está em déficit. Necessita de ampliação imediata em mais 2.200 1/s. Com o crescimento decorrente da implantação do Complexo Petroquímico - COMPERJ na região, o sistema precisará de nova ampliação para atender a uma demanda projetada de 12.500 1/s até 2030"
} 
Companhia Estadual de Águas e Esgotos do Rio de Janeiro, o agente causador direto do problema pode ter sido a presença de grande quantidade de geosmina ${ }^{54}$.

Entretanto, a nota técnica da Universidade Federal do Rio de Janeiro ${ }^{55}$, elaborada a partir dos laudos divulgados na data de quinze de janeiro do ano de 2020, informou que não havia referência à indicação da presença de quantidade de geosmina na água capaz de justificar tal alteração na sua qualidade.

Os impactos decorrentes do despejo de rejeitos do setor industrial não foram apontados explicitamente como agentes causadores da poluição no Rio Guandu, a Federação das Indústrias do Rio de Janeiro (FIRJAN) inclusive reiterou essa narrativa de que a origem está na histórica falta de investimentos em saneamento básico no Estado e não na operação das indústrias.

Contrapondo tal perspectiva, em fevereiro de 2020, após fiscalização realizada pela Secretaria de Estado do Ambiente e Sustentabilidade e pelo Instituto Estadual do Ambiente no distrito industrial de Queimados, próximo ao sistema Guandu, onde existem 32 empresas internacionais e nacionais de diversos setores, como alimentício, frigorífico, têxtil, material de construção e cosméticos, há conhecimento de que muitas dessas empresas foram autuadas: algumas fechadas e outras multadas ${ }^{56}$, exatamente por poluírem o Rio Guandu.

Tais fatos reforçam a questão das incertezas vinculadas às reais causas da alteração "visível" na qualidade da água que é distribuída para a população da Região Metropolitana do Rio de Janeiro. A geosmina é um composto orgânico que cresce em ambientes aquáticos especialmente em mananciais que recebem esgoto não tratado, no entanto, ela não promove mudança de cor ou turbidez na água, fato que coloca em questão dois pontos principais: o primeiro está relacionado com a não conclusão sobre todas as possíveis causas vinculadas ao problema; o segundo está no posicionamento de diversos especialistas de que, o principal motivo causador da alteração de qualidade da água está no despejo de esgoto doméstico sem tratamento dos afluentes (1 - Rios Poços/Queimados e 2- Cabuçu/Ipiranga) ${ }^{57}$ na Bacia Hidrográfica do Rio Guandu. Investimentos em infraestrutura e a instalação de Unidades de Tratamentos de Resíduos nesses afluentes, certamente minimizaria os efeitos produzidos pelo lançamento de esgoto na Lagoa do Rio Guandu, mas também não se pode negligenciar a necessidade de se solucionar o problema da poluição produzidas pelas indústrias dessa região.

Para solucionar o problema de lançamento de esgotos dos afluentes do Rio Guandu na lagoa de captação de água, foram elaborados pelo Laboratório de Hidrologia e Estudos Ambientais do Instituto Alberto Luiz Coimbra de Pós-Graduação e Pesquisa de Engenharia (COPPE) da Universidade Federal do Rio de Janeiro (UFRJ), em 2011, o projeto de Obras de Proteção da

\footnotetext{
<http://200.20.53.26:8080/cs/idcplg?IdcService=GET_FILE\&dID=84748\&dDocName=INEA0068928\&allowIn terrupt $=1>$.

${ }^{54}$ Conferir o significado de Geosmina na Wikipédia: <https://pt.wikipedia.org/wiki/Geosmina〉.

${ }^{55}$ Sobre a contaminação dos mananciais da RMRJ, ler a "Nota técnica da UFRJ sobre os Problemas da qualidade da água que a população do Rio de Janeiro está vivenciando" < https://ufrj.br/sites/default/files/imgnoticia/2020/01/nota_tecnica_-_caso_cedae.pdf>.

${ }^{56}$ Disponível em <https://oglobo.globo.com/rio/duas-empresas-sao-fechadas-durante-operacao-para-identificardespejo-de-esgoto-sem-tratamento-no-guandu-24232325>.

57 Consultar: a) Dias e Dieile da Silva 2016, p. 94; b) Girota 2016, p 208; c) Volschan Jr 2020 $<$ https://www.plurale.com.br/site/noticias-

detalhes.php?cod=17303\& $\operatorname{codSecao}=11 \&$ oMnu=especiais $\&$ sub=agua $>$.
} 
Tomada D'água da Companhia Estadual de Águas e Esgotos do Rio de Janeiro no Rio Guandu e o Relatório de Impacto Ambiental (RIMA).

Estas duas ações seriam implantadas pela empresa Construtora Metropolitana S/A, contratada por licitação em 2013 pela Companhia Estadual de Águas e Esgotos do Rio de Janeiro, com recursos do Programa de Aceleração do Crescimento (PAC), por meio do projeto "Saneamento para Todos".

O projeto previa a "construção de um dique associado a estruturas hidráulicas de desvio, que impediriam a chegada do esgoto dos afluentes do Rio Guandu à lagoa de captação de água para a estação"58 (Figura 5); mas essa obra que estava sendo executada pela Construtora Metropolitana S/A foi embargada pelo Ministério Público em março 2015, que a acusou de prática ilegal de sobre preço.

Figura 5. Projeto de Obras de Proteção da Tomada D'água da CEDAE no Rio Guandu

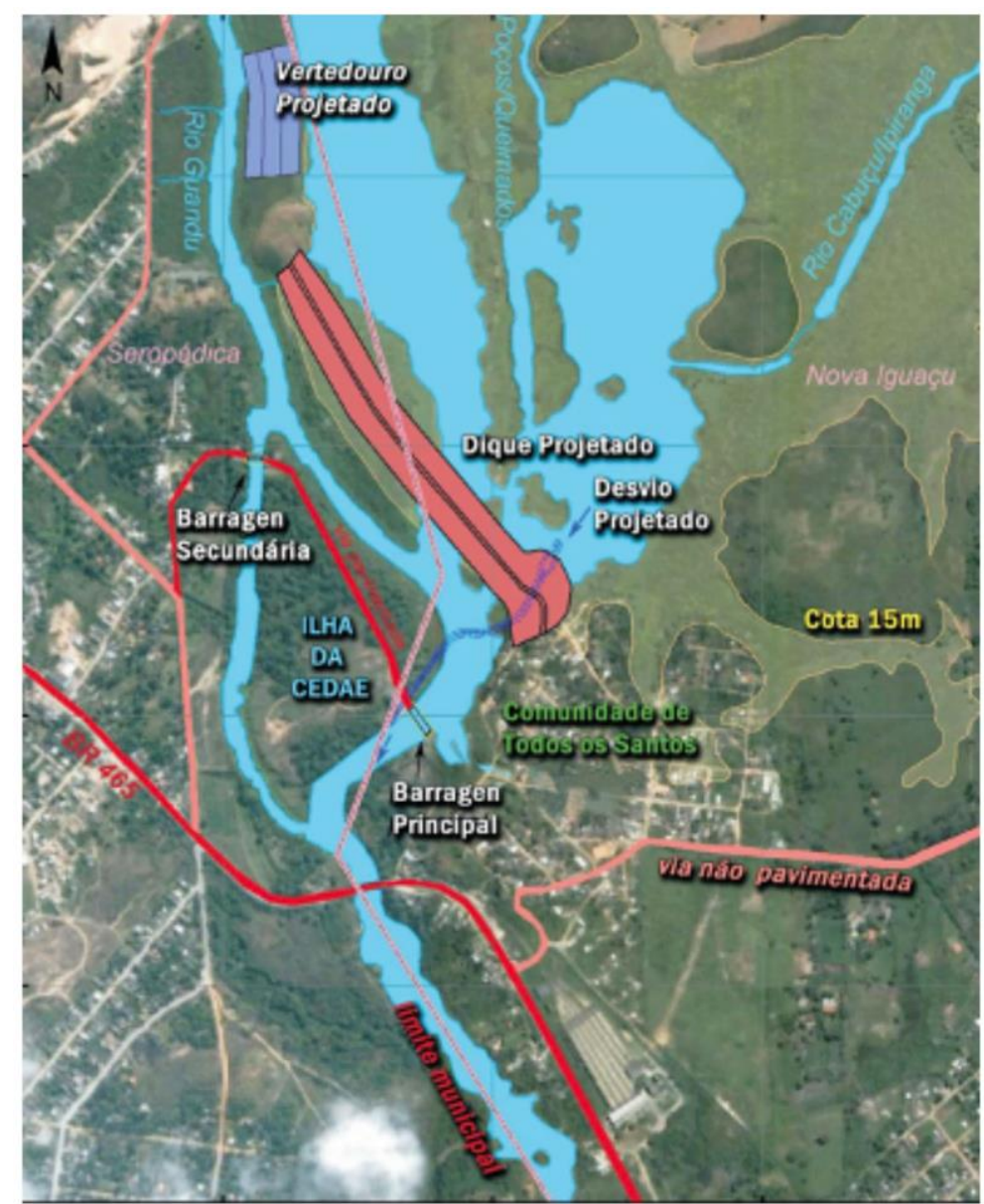

Fonte: Relatório de Impacto Ambiental - RIMA. Rio de Janeiro: 2011 <http://www.ceivap.org.br/downloads2011/CEDAE_RIMA.pdf>.

\footnotetext{
${ }^{58}$ Ver reportagem "Cedae engaveta por 10 anos obra que evitaria contaminação de agua no Rio" de Igor de Mello, publicada no portal UOL em 19 de janeiro de 2020: 〈https://noticias.uol.com.br/cotidiano/ultimasnoticias/2020/01/19/cedae-engaveta-por-10-anos-obra-que-evitaria-contaminacao-de-agua-no-rio.htm>.
} 
No entanto, investimentos estratégicos das instâncias governamentais municipais, estaduais e federal e do setor industrial e energético dessa região poderiam contribuir para minimizar essa crise de abastecimento e saneamento à população e, como aconteceu em Barcelona, Ilhas Baleares $^{59}$, e Israel ${ }^{60}$, a construção de uma usina de dessalinização da água do mar poderia solucionar o problema de abastecimento de água para a região metropolitana, que não dependendo da água desses rios, propiciaria mais recursos hídricos para as regiões que dependem apenas desse manancial fluvial.

\section{Conflitos pelo abastecimento público na Região Metropolitana do Rio de Janeiro}

A situação de escassez hídrica é agravada pelos usos distintos e conflitantes da água, o poder estatal tende a oferecer grandes volumes hídricos captados, mas também concede, por meio de isenções fiscais, subvenções que deveriam ser cobradas.

A captação outorgada para a Companhia Estadual de Águas e Esgotos do Rio de Janeiro nesta bacia abastece milhões de pessoas em quinze municípios. Parte dessa água captada é destinada a centenas de corporações industriais (48\%); no entanto, em condições normais de vazão, as indústrias dessa região não sofreram com desabastecimento de água, enquanto nove desses quinze municípios abastecidos pelas águas da $\mathrm{BH}$ Guandu enfrentaram problemas de abastecimento, foram os casos de: "Itaguaí, Seropédica, Queimados, Japeri, Paracambi (totalmente inseridos na bacia do Guandu), Barra do Piraí, Nova Iguaçu, Rio Claro e Rio de Janeiro (parcialmente inseridos na bacia do Guandu)" ${ }^{\prime}$. É possível afirmar isso quando utilizamos dados constantes no Relatório Síntese sobre o Plano Estratégico da Região Hidrográfica do Guandu, de $2014^{62}$.

Contudo, acessar a rede de distribuição de água não garante um fornecimento adequado, sobretudo nas zonas periféricas da Região Metropolitana do Rio de Janeiro, nos municípios de Duque de Caxias, Nova Iguaçu, Queimados, Belford Roxo, Paracambi e Japeri, onde o fornecimento de água ocorre de duas a três vezes por semana ${ }^{63}$. No entanto, contraditoriamente, na região da baixada fluminense, no âmbito do abastecimento público, via sistema ParaíbaGuandu/Lajes/Acari, existem infraestruturas, como sistema de adução e reservatórios, construídos para atendimento das atividades industriais ${ }^{64}$, citando apenas dois exemplos: a

\footnotetext{
${ }^{59}$ Ver March y Saurí 2010, p.18.

${ }^{60}$ Ministry of Finance 2020: <https://www.gov.il/en/departments/general/project-water-desalination-

background\#: :text=Israel's\%20current\%20scope \%20of\%20desalination, the \%20Ashdod\%20plant\%20100\%20

million>.

${ }^{61}$ Conferir em <https://www.comiteguandu.org.br/downloads/Relatorio\%20de\%20Situacao\%20-

$\%$ 20Guandu.pdf>

62 Disponível em

$<$ http://arquivos.ana.gov.br/institucional/sge/CEDOC/Catalogo/2007/PlanoEstrategicoRHGuanduRelatorioSintes e.pdf>

${ }^{63}$ Leite in Britto et al. 2016, p. 196: "Segundo o técnico do Departamento de Águas e Esgotos (DAE-CEDAE) de Queimados, departamento que atende, efetivamente, Queimados, Japeri e Paracambi, diversos bairros desses municípios são atendidos com manobras de água, a saber, a população recebe água durante dois dias para em seguida ficar três dias sem água. Já no caso de Duque de Caxias, o Secretário de Urbanismo afirmou, em apresentação realizada do Seminário Rio Metropolitano em 05/05/2015, que vários bairros sofrem com abastecimento intermitente (os moradores recebem água somente 3 a 4 dias por semana) e que regiões do $2^{\circ}$ e 30 distritos (Imbariê e Xerém) sequer possuem rede de abastecimento".

${ }^{64}$ Britto et al., 2016.
} 
Refinaria da Petrobrás em Duque de Caxias (REDUC), mais precisamente no distrito de Campos Elísios ${ }^{65}$, e o Polo Industrial no município de Queimados ${ }^{66}$.

\section{Contradições do consumo por setores usuários na Bacia Hidrográfica do Rio Guandu}

De acordo com dados do Plano Estadual de Recursos Hídricos (PERHI-RJ, 2014), a demanda de uso da água no estado do Rio de Janeiro indica que o setor industrial é o que mais consome água, com $43 \%$, seguido respectivamente pelo abastecimento humano com $42 \%$, agricultura com $13 \%$ e mineração e criação animal $1 \%{ }^{67}$.

No Estado do Rio de Janeiro, o gerenciamento da água é feito pelo Instituto Estadual do Ambiente, que possui além dessa competência outras atribuições, como a concessão de outorga legal de uso àqueles que necessitam parte dos recursos hídricos do Estado para o desenvolvimento de suas atividades empresariais ${ }^{68}$.

A outorga legal, atribuída pelo poder concedente do estado, transforma alguns agentes privados em usuários privilegiados dos recursos hídricos e relega a prioridade do consumo à maioria da população consumidora das águas do Rio Guandu. Esse processo ajuda a entender como o processo de escassez hidrossocial é socialmente produzido.

Nesse sentido, pode-se considerar como usuários aqueles entes que possuem outorga para captação da água do sistema Guandu, tanto empresas de abastecimento público como indústrias específicas.

A Companhia Estadual de Águas e Esgotos do Rio de Janeiro é um exemplo de empresa pública usuária de água na bacia do Rio Guandu. Os consumidores, por sua vez, são pessoas, grupos sociais, equipamentos urbanos ou entidades, captadoras da água e de serviços coletivos de esgotamento sanitário realizados e distribuídos pela Companhia Estadual de Águas e Esgotos do Rio de Janeiro.

A maior concentração de empresas privadas do setor industrial, usuárias com direitos outorgado para utilizarem as águas da BH do Rio Guandu, está localizada nas margens do Canal de São Francisco e na tríplice fronteira dos municípios do Rio de Janeiro, Seropédica e Nova Iguaçu. São os casos: siderúrgicas (Gerdau/Cosigua, CSN e CSA), termoelétricas (Inepar e UTE Santa Cruz) e petroquímica (Fábrica Carioca de Catalisadores) e com a presença de indústrias

\footnotetext{
${ }^{65}$ Cf. Lemes in Britto et. al. 2016 p. 198 "Com o decorrer dos anos, a expansão das instalações da REDUC aumentou a sua demanda por água, quando se optou por um manancial que garantisse o atendimento às suas demandas atuais e futuras: o rio Guandu, próximo à captação da ETA Guandu. Este sistema de captação da REDUC é composto por uma elevatória, com capacidade de até $7.200 \mathrm{~m} 3 / \mathrm{h}$, e uma adutora de 32 " $(81,28 \mathrm{~cm}) \mathrm{de}$ diâmetro que percorre $48 \mathrm{~km}$ atravessando os municípios de Nova Iguaçu, Belford Roxo e Duque de Caxias até chegar à REDUC. Este sistema é operado pela CEDAE, mas não passa por todos os processos de tratamento na ETA Guandu, apenas por tanques de decantação. Em 2007, esse sistema respondia pelo suprimento de $48 \%$ das necessidades da REDUC $(1.246 \mathrm{~m} 3 / \mathrm{h})$ e $85 \%$ das necessidades das indústrias do polo gás-químico $(850 \mathrm{~m} 3 / \mathrm{h})$ totalizando uma vazão total de $2.096 \mathrm{~m} 3 / \mathrm{h}$ ".

${ }^{66}$ Britto et al. 2016, p. 198. "Um dos reservatórios existentes no município está localizado dentro do Distrito Industrial de Queimados (Reservatório da CODIN), que é abastecido com 200 1/s de água proveniente do Ribeirão das Lajes. É uma água de boa qualidade, destinada ao abastecimento industrial, em um município onde há carência de acesso regular para a maior parte da população."

${ }^{67}$ Cinco 2016, p. 21.

${ }^{68}$ Pinto 2010, p.113.
} 
petroquímicas (Riogen-Eron) e de bebidas (Cervejarias Brahma e Kaiser), próximas ao ponto de captação da Estação de Tratamento de Água do Rio Guandu respectivamente ${ }^{69}$.

O setor industrial, sobretudo o existente na bacia do Guandu, apresenta-se, proporcionalmente, como o maior demandador de águas fluviais ${ }^{70}$. Informações sobre o balanço hídrico relatadas no livro Bacia Hidrográfica dos Rios Guandu e Guandu Mirim, elaborado pelo Comitê de Bacia Hidrográfica do Guandu em conjunto com o Instituto Estadual do Ambiente, atestam essa constatação.

Segundo o INEA, a Bacia Hidrográfica do Rio Guandu, até início de 2012, possuía um total de 45 outorgas em vigor ${ }^{71}$, naquele ano a disponibilidade hídrica total outorgável do Rio Guandu correspondeu a $130 \mathrm{~m}^{3} / \mathrm{s}$ enquanto a média anual total da vazão apresentou um volume de $187,56 \mathrm{~m} 3 / \mathrm{s}$. Ou seja, em relação à vazão total, aproximadamente $69 \%$ do volume hídrico da bacia foi permitida para outorga. Oito outorgas destinavam-se à Companhia Estadual de Águas e Esgotos do Rio de Janeiro, sendo que uma não era destinada ao abastecimento público e sim para produção da Cerveja Cintra, adquirida posteriormente pela Ambev em 2007.

Considerando a diferença entre o volume hídrico captado sobre o lançado novamente à bacia hidrográfica, as outras trinta e sete outorgas não se destinavam ao abastecimento público. As outorgas vinculadas ao abastecimento público captaram $64,55 \mathrm{~m}^{3} / \mathrm{s}(21 \%)$ enquanto as demandadas pelo setor industrial e energético captaram $239,03 \mathrm{~m}^{3} / \mathrm{s}(79 \%)^{72}$.

Entre as 45 empresas e instituições outorgadas ${ }^{73}$ para operar como prestadora dos serviços de abastecimento público e esgotamento sanitário, a Companhia Estadual de Águas e Esgotos do Rio de Janeiro foi a companhia que realizou mais de $99 \%$ das operações de abastecimento de água na Bacia Hidrográfica do Rio Guandu, mas em relação ao esgotamento sanitário, a Prefeitura de Nova Iguaçu realizou o tratamento de apenas 1\% do esgoto sanitário na baixada fluminense $^{74}$. A Light (Paraíba do Sul/Guandu), foi a empresa de geração de energia que mais captou, totalizando 210 m³/s (69\%) das águas da Bacia Hidrográfica do Rio Guandu.

\section{A outorga de concessão legal do saneamento básico, do abastecimento e cobrança da água}

A formulação da Lei $n^{\circ}$ 9.433/97 ${ }^{75}$ teve por objetivos instituir a Política Nacional de Recursos Hídricos e criar o Sistema Nacional de Gerenciamento de Recursos Hídricos, na SEÇÃO IV, DA COBRANÇA DO USO DE RECURSOS HÍDRICOS, nos Art. 19, 20 e 21, ficou promulgado que a água é um recurso hídrico de domínio público e, ao mesmo tempo, é um bem econômico dotado de valor ${ }^{76}$.

\footnotetext{
${ }^{69}$ Castro e Ferreirinha 2015, p. 73.

${ }^{70}$ Araújo 2016, p. 68 "De norte a sul do nosso País, o que se vê é que o agronegócio, indústrias pesadas (siderúrgicas, refinarias), a geração de energia (termelétricas consomem bastante água), a mineração etc. são consumidores vorazes de água. Uma única usina termelétrica a carvão pode consumir até 1000 litros de água por segundo, suficiente para abastecer uma cidade quase do tamanho de São José dos Campos (SP)”.

${ }^{71}$ Conferir Tubbs Filho et al 2012, Tabela 2, p. 108-110.

${ }^{72}$ Idem, Tabela 2, p. 108-110.

${ }^{73}$ Ibidem, Tabela 2, p. 108-110.

${ }^{74}$ Conferir em: <https://extra.globo.com/noticias/rio/estudo-aponta-que-cinco-cidades-da-baixada-fluminensenao-fazem-tratamento-de-esgoto-rv1-1-24534068.html>.

${ }^{75}$ Cf. a Lei 9.433/97 <http://www.planalto.gov.br/ccivil_03/Leis/L9433.htm>.

${ }^{76}$ Pinto 2010, p. 59, e Santilli 2001, p.145.
} 
Essa decisão, via legislação pode ser entendida como um desdobramento dos movimentos ambientalistas, sobretudo da Declaração de Dublin, fruto da Conferência Internacional de Água e Meio Ambiente (ICWE) em 1992. No entanto, se esse bem se torna "escasso", o valor alavancado pela sua procura pode transformá-lo em uma mercadoria.

As causas das sucessivas crises hídricas na cidade do Rio de Janeiro e Região Metropolitana quando entendidas em conjunto ao contexto socioespacial atual, somado às previsões climáticas, sugerem também uma possibilidade previsível de colapso hídrico na Região Metropolitana do Rio de Janeiro ou parte dela. O colapso nada mais é que o último estágio do processo de escassez, a partir da previsibilidade desse contexto.

A concessão da Companhia Estadual de Águas e Esgotos do Rio de Janeiro para o setor privado foi uma das condições estabelecidas para que o governo do Rio de Janeiro ingressasse no Regime de Recuperação Fiscal, proposto em 2017 pela União. Foi exigido uma divisão em quatro áreas ou blocos de municípios $^{77}$, com a possibilidade de cada bloco ter uma concessionária diferente que poderia atender partes da cidade do Rio de Janeiro.

O projeto neoliberal apresentado pelo governo do Estado do Rio de Janeiro em $2020^{78}$ indica que as áreas de saneamento básico, distribuição e cobrança de água deverão ser concedidos, enquanto a captação e o tratamento da água continuarão sob a responsabilidade da Companhia Estadual de Águas e Esgotos do Rio de Janeiro ${ }^{79}$.

Na prática, esse desmembramento favorece o setor privado, pois este passa a gerenciar o capital arrecadado pela cobrança da água, enquanto o setor público, no caso do Estado do Rio de Janeiro já muito endividado, fica com os custos de manutenção da estrutura hidráulica e tratamento da água, ou seja, retira-se o mecanismo de arrecadação pela cobrança do serviço, mas mantém-se os custos de operação para, supostamente, ajustar as contas do estado ao Regime de Recuperação Fiscal, uma contradição lógica e perversa, que prejudica o patrimônio conquistado pela população fluminense.

Além disso, no início de 2020, o governador do Rio de Janeiro na ocasião informou, em reunião do Conselho Deliberativo da Região Metropolitana, que as obras de ampliação do Sistema Guandu para a captação e o tratamento da água, seriam realizadas, a partir da privatização da Companhia Estadual de Águas e Esgotos do Rio de Janeiro, nos moldes indicados anteriormente. $\mathrm{O}$ governo estadual, neste caso, condicionou a expansão de serviços essenciais para garantia de direitos universais à privatização. O favorecimento ao setor privado foi ampliado pois, mais uma vez, o ente público arcaria com os custos do investimento para o setor privado se aproveitar posteriormente.

De acordo com o Conselho que acompanhou as etapas do processo de privatização, em janeiro de 2020, a segunda fase do processo estava atrasada ${ }^{80}$. No mesmo mês, o governo informou sobre a possibilidade de valorização da Companhia Estadual de Águas e Esgotos do Rio de Janeiro, em até o dobro do valor estimado na época, devido a investimentos realizados em uma nova estação de tratamento de água na Região Metropolitana do Rio de Janeiro. É possível que

\footnotetext{
${ }^{77}$ Disponível em <https://agenciabrasil.ebc.com.br/economia/noticia/2019-12/privatizacao-da-cedae-seradividida-em-quatro-blocos-de-municipios $>$.

${ }^{78}$ Representado pelo Governador temporariamente afastado Wilson Witzel

${ }^{79}$ Disponível em <http://www.rj.gov.br/consultapublica/>.

${ }^{80}$ Disponível em <https://g1.globo.com/rj/rio-de-janeiro/noticia/2020/01/04/relatorio-aponta-atraso-do-governodo-rj-para-a-privatizacao-da-cedae.ghtml>.
} 
o atraso no processo estivesse diretamente relacionado à especulação sobre o valor da empresa, o que fez sentido se considerarmos a atual situação fiscal do Estado.

A inserção da iniciativa privada na administração pública de serviços essenciais não garante sua universalização por si só, nem significa maiores investimentos e também não necessariamente soluciona as complexas questões que envolvem o processo de escassez hídrica da Região Metropolitana do Rio de Janeiro, embora esses tenham sido os principais temas utilizados para justificar a concessão da Companhia Estadual de Águas e Esgotos do Rio de Janeiro ${ }^{81}$.

Nesse sentido, é muito provável que a política neoliberal de privatização da Companhia Estadual de Águas e Esgotos do Rio de Janeiro, além de não solucionar os problemas complexos, deverá agravar as situações já existentes de falta de água, sobretudo nas zonas periféricas, onde estão as populações com menos recursos financeiros para pagar por esse serviço.

Além disso, a perda da arrecadação do Estado com a possível venda da Companhia Estadual de Águas e Esgotos do Rio de Janeiro pode agravar ainda mais a crise fiscal em que se encontra o Estado do Rio de Janeiro, uma vez que ele é o principal ente federativo responsável por gerenciar toda a rede de relações que envolve a economia e prestação dos serviços de fornecimento das águas no território.

Essa atribuição, que vem sendo mal desempenhada, gera o argumento utilizado para privatizar importantes empresas estatais de utilidade pública, alegando a falta de "capacidade" do Estado em solucionar ou mitigar problemas que afetam a água e a sociedade. No entanto, o Estado vai continuar arcando com a parte mais difícil e de maiores custos operacionais, para efetuar a captação e o tratamento da água.

Porém, no momento de decisão sobre a concessão da água para o setor privado, alguns membros do poder legislativo dos partidos de ideologia neoliberal, que possuem poder de voto e veto, tendem a atender mais aos interesses usurpadores do capital e das grandes corporações do que os interesses da maioria da população.

\section{Ações políticas e possibilidades para enfrentamento da crise hídrica}

“A pobreza é uma situação de carência, mas também de luta, um estado vivo, de vida ativa, em que a tomada de consciência é possível. Mas os pobres não se entregam. Eles descobrem cada dia formas inéditas de trabalho e de luta. Assim, eles enfrentam e buscam remédio para suas dificuldades" (Milton Santos, 2000, p.132).

Para a governança do sistema hídrico é possível elencar um conjunto de ações políticas que podem mitigar as consequências das causas referentes à escassez hídrica, como: a) adoção de tecnologias preventivas e infraestrutura de engenharia remediadoras para as localidades diretamente afetadas pelo processo de escassez e suas possíveis configurações; b) desenvolvimento de novas técnicas para construção de sistemas de coleta e armazenamento água da chuva; c) emprego de técnicas de descontaminação e tratamento da água; d) emprego

\footnotetext{
${ }^{81}$ Conferir reportagem do Portal G1 em <https://g1.globo.com/rj/rio-de-janeiro/noticia/2020/01/04/relatorioaponta-atraso-do-governo-do-rj-para-a-privatizacao-da-cedae.ghtml>.
} 
de técnicas de incentivo ao reflorestamento; e) desenvolvimento de técnicas de reflorestamento para diversos fins e dessalinização de água do mar, principalmente na vertente voltada para o oceano; f) estímulo à diminuição da circulação e consumo de produtos poluidores; g) fomento de campanhas educacionais contínuas, relacionadas ao descarte apropriado de resíduos sólidos e líquidos; h) apresentação de situações problemáticas, resultantes do descarte de resíduos tóxicos ou contaminantes na rede hidrográfica, entre outras.

A concepção e a sistematização de um conjunto de ações políticas, que propomos, com relação ao debate multissetorial, para fazer frente à escassez hídrica, produzida por políticas neoliberais, foram resultantes de levantamentos de dados e pesquisas que de alguma forma são compatíveis às medidas selecionadas.

A seguir relacionamos um conjunto de vinte e seis (XXVI) ações políticas e quarenta e quatro (44) estratégias possíveis, algumas destas ações são resultantes de pesquisas, debates e fóruns estabelecidos em diferentes frentes e escalas local, nacional e global ${ }^{82}$, para o enfrentamento do processo da crise hídrica no Rio de Janeiro (Quadro 1).

\section{Quadro 1. Conjunto de políticas propostas. Estratégias e Alternativas Possíveis}

\begin{tabular}{|c|c|}
\hline $\begin{array}{c}\text { Conjunto de Ações Políticas Propostas e } \\
\text { Referências }\end{array}$ & $\begin{array}{l}\text { Estratégias/Alternativas Possíveis } \\
\text { e Referências }\end{array}$ \\
\hline $\begin{array}{l}\text { I. Resistência ao modelo neoliberal de } \\
\text { privatização. Cinco, 2016; Bittencourt e Serafini } \\
2016 .\end{array}$ & $\begin{array}{l}01 \text { - Intensificar campanhas "Água como Direito Humano } \\
\text { Fundamental". Cinco, 2016; Oliveira } 2016 . \\
02 \text { - Suspender processos de privatização e concessões em } \\
\text { curso. Oliveira, 2016; Lowy } 2016 .\end{array}$ \\
\hline $\begin{array}{l}\text { II. Denuncia de problemas com o modelo de } \\
\text { concessão e privatização da água. Bittencourt \& } \\
\text { Serafini } 2016 \text {. }\end{array}$ & $\begin{array}{l}03 \text { - Incentivar acesso às informações sobre privatização da } \\
\text { água no mundo. Azpiazu e Castro } 2016 .\end{array}$ \\
\hline $\begin{array}{l}\text { III. Aperfeiçoamento do sistema de outorga } \\
\text { hídrica superficial e subterrânea. Carneiro } 2016 .\end{array}$ & $\begin{array}{l}04 \text { - Estabelecer procedimentos eficazes e regulares de } \\
\text { fiscalização da outorga hídrica. Carneiro } 2016 \text {. }\end{array}$ \\
\hline $\begin{array}{l}\text { IV. Transparência dos dados sobre outorga de } \\
\text { água. Araújo } 2016 \text {. }\end{array}$ & $\begin{array}{l}05 \text { - Renovar Comissão Especial sobre o Colapso Hídrico } \\
\text { anualmente. Crise Hídrica em Debate (CHD) } 2016 .\end{array}$ \\
\hline $\begin{array}{l}\text { V. Implantação do sistema unificado de outorga } \\
\text { na Bacia Hidrográfica do Rio Paraíba do Sul. } \\
\text { Carneiro } 2016 \text {. }\end{array}$ & $\begin{array}{l}06 \text { - Sistematizar dados por meio de planos municipais de } \\
\text { tratamento e saneamento da água. Bittencourt e Serafini } \\
2016 \text {. }\end{array}$ \\
\hline $\begin{array}{l}\text { VI. Constituição do Observatório das Águas } \\
\text { integrado das BH do Paraíba e Guandu. Crise } \\
\text { Hídrica em Debate (CHD) } 2016 \text {. }\end{array}$ & $\begin{array}{l}07 \text { - Fortalecimento do Observatório das Águas no Rio de } \\
\text { Janeiro. Le Strat } 2016 .\end{array}$ \\
\hline $\begin{array}{l}\text { VII. Elaboração de planos de contingências. } \\
\text { Carneiro } 2016 .\end{array}$ & $\begin{array}{l}08 \text { - Promover a organização de comitês de bacias e grupos } \\
\text { de trabalho sob a direção do Instituto Estadual do Ambiente } \\
\text { (INEA), da Companhia Estadual de Águas e Esgotos do Rio } \\
\text { de Janeiro e da Empresa Brasileira de Pesquisa Agropecuária } \\
\text { (EMBRAPA), com a participação das Universidades e } \\
\text { também da sociedade civil organizada. Proposta nossa. } \\
09 \text { - Executar avaliação da disponibilidade hídrica junto com } \\
\text { às projeções de demandas futuras. Branco 2006; Queiroz, } \\
\text { 2012; Coutinho 2019. }\end{array}$ \\
\hline $\begin{array}{l}\text { VIII. Fortalecimento da governança } \\
\text { metropolitana aberta da água. Le Strat } 2016 .\end{array}$ & $\begin{array}{l}10 \text { - Articular os comitês de bacias, com o poder público e a } \\
\text { sociedade civil organizada. Pinto 2010; Castro e Ferreirinha } \\
2012 \text {. }\end{array}$ \\
\hline
\end{tabular}

\footnotetext{
${ }^{82}$ Conferir CHD 2016, p. 49.
} 
IX. Aplicação de instrumentos previstos na lei
9.433/97. Pinto, 2010; Santilli 2001.

X. Fortalecimento de programas de educação ambiental popular crítica. Crise Hídrica em Debate (CHD) 2016.

XI. Promoção de eventos para a participação das comunidades afetadas. Bittencourt e Serafini 2016.

XII. Implementação de programas de educação e capacitação de recursos humanos para a gestão social de recursos hídricos. Tundsi e Tundsi 2015

XIII. Garantia da prioridade do abastecimento para a população. CHD 2016.

XIV. Redução da demanda hídrica pelos múltiplos usos. Tundsi e Tundsi 2015.

na indústria. Carneiro 2016.
11 - Executar a integração da gestão hídrica à gestão ambiental. Faria, Rocha e Gomes 2008; Pizella 2015.

12 - Incentivar trabalho de campo científico-pedagógico na Bacia Hidrográfica do Rio Guandu, com a participação das Universidades e também da Sociedade Civil organizada (ONG) e instituições de Ensino Básico. Proposta nossa.

13 - Promover a formação de espaços de diálogo para a comunidade afetada expor seus problemas. Proposta nossa. 14 - Dialogar e capacitar comunidades locais na gestão compartilhada dos recursos hídricos. Bittencourt e Serafini; Lowy 2016.

15 - Empreender política públicas de educação sobre a gestão dos recursos hídricos com técnicos, gestores e pesquisadores. Young et al. 2015.

16 - Proteger o sistema de captação de água do Rio Guandu e garantir prioridade para abastecimento da população da Região Metropolitana do Rio de Janeiro. Dertoni et al 2011; Azpiazu e Castro 2016; Pigeon 2016; Oliveira 2016.

17. Oferecer acesso a água potável e reduzir tarifas e taxas nas contas de água à população de baixo poder econômico afetada com a falta d'água. Pigeon, 2016; Azpiazu e Castro 2016.

18 - Mobilizar tecnologia avançada para este fim. Tundsi e Tundsi 2015.

19 -Redução de gases do efeito estufa. Melo e Marques 2016; Araújo 2016.

20 - Reduzir desperdício de água na rede. Tundsi e Tundsi 2015.

21 - Renovação da infraestrutura com tecnologias mais avançadas. Tundsi e Tundsi 2015.

22 - Investir equipamentos certificados de menor consumo de água. Carneiro 2016

23 - Estabelecer políticas tarifárias proporcionais ao uso. Carneiro 2016.

XVI. Implementação de políticas públicas para o reuso e aproveitamento da água da chuva. Carneiro 2016.

XVII. Tratamento dos esgotos despejados in natura nos rios que drenam a Região Metropolitana do Rio de Janeiro e reaproveitamento e reuso de água proveniente do tratamento de esgotos nas Unidades de Tratamento de Esgotos. Carneiro 2016.

24 - Sistema Azul e Verde da Ecotelhado. Verran 2015.

25 - Sistema Aqualuz purificação e desinfecção por radiação solar. Ver método de Anna Luisa Santos, in Alves 2019.

26 - Elaborar Relatório de Impacto Ambiental e Plano de Manejo da Área de Proteção Ambiental do rio Guandu (APA Guandu). Dertoni et al 2011.

27 - Elaborar políticas públicas intersetoriais de saneamento ambiental. Dias e Daile Silva; Girota 2016.

28 - Restaurar a Mata Ciliar com plantas macrófitas. Julyenne Campos, Denis Roston, Sonia Queiroz 2019.

29 - Implantar fossas biodigestoras em domicílios da APA Guandu. Embrapa 2010.

30 - Obrigar as indústrias a criar miniestações de tratamento de esgoto em zonas urbanas. Bittencourt e Serafini 2016.

XVIII. Revitalização dos rios das redes 31 - Estabelecer padrões para água de reuso e o tratamento hidrográficas dentro das zonas urbanas da de esgotos. Hespanhol 2010.

Região Metropolitana do Rio de Janeiro. Proposta nossa.

32 - Reutilizar água provenientes do esgoto. Tundsi e Tundsi 2015.

XIX. Democratização de técnicas de 33 - Remunicipalizar o sistema urbano de água a partir de abastecimento e conservação da água. Proposta nossa.

XX. Ampliação da Estação de Tratamento de Água do Rio Guandu em 36.000 1/s. Carneiro 2016. uma da gestão compartilhada da água. Pigeon 2015; Bittencourt e Serafini 2016.

34 - Financiar Companhia Estadual de Águas e Esgotos do Rio de Janeiro por meio de impostos e tributos provenientes dos setores industrial e elétrico. Pinto 2010. 


\begin{tabular}{|c|c|}
\hline $\begin{array}{l}\text { XXI. Investimento em novas tecnologias. } \\
\text { Tundsi e Tundsi } 2015 \text {. }\end{array}$ & $\begin{array}{l}35 \text { - Monitorar qualidade da água em tempo real com } \\
\text { imagens de satélite. Ogashawara et. Al. } 2014 . \\
36 \text { - Reflorestar mananciais com espécies nativas. Hupfer, } \\
\text { Figueiredo \& Tundisi } 2013 \text {. } \\
37 \text { - Restaurar os ecossistemas dos rios. Anelli } 2015 \text {. } \\
38 \text { - Revitalizar parques municipais como mecanismo de } \\
\text { reposição de águas. Buckeridge } 2015 \text {. } \\
39 \text { - Sistematizar dados: saúde humana, qualidade das águas, } \\
\text { usos e ocupação do solo. Tundsi e Tundsi } 2015 \text {. }\end{array}$ \\
\hline $\begin{array}{l}\text { XXII. Promoção de políticas de reflorestamento } \\
\text { alternativo na Bacia Hidrográfica do Rio } \\
\text { Guandu. CHD } 2016\end{array}$ & $\begin{array}{l}40 \text { - Mesclar o reflorestamento de espécies nativas com } \\
\text { agroflorestas. Proposta nossa. }\end{array}$ \\
\hline $\begin{array}{l}\text { XXIII. Revitalização e preservação de pequenos } \\
\text { mananciais. Carneiro } 2016 .\end{array}$ & $\begin{array}{l}41 \text { - Conservar as áreas de cotas mais altas para revitalizar } \\
\text { nascentes. Proposta nossa. }\end{array}$ \\
\hline $\begin{array}{l}\text { XXIV. Construção de reservatórios em } \\
\text { afluentes do rio Paraíba do Sul. Carneiro } 2016 .\end{array}$ & $\begin{array}{l}42 \text { - Promover audiências públicas entre governo e } \\
\text { sociedade civil, com a participação das Universidades. Le } \\
\text { Strat } 2016 \text {. }\end{array}$ \\
\hline $\begin{array}{l}\text { XXV. Realização de } \\
\text { perfuração de poços, seleção dos equipamentos } \\
\text { e execução obras necessárias } \\
\text { em consonância com a política estadual de } \\
\text { recursos hídricos. Carneiro } 2016 \text {. }\end{array}$ & $\begin{array}{l}43 \text { - Desenvolver um plano estadual de exploração de águas } \\
\text { subterrâneas. Pinto, } 2010 \text { e Carneiro } 2016 .\end{array}$ \\
\hline $\begin{array}{l}\text { XXVI. Investimento em projetos para } \\
\text { dessalinização da água do mar, utilizando } \\
\text { energia solar. Carneiro 2016. }\end{array}$ & $\begin{array}{l}44 \text { - Investir no sistema Aquasolina. Ver método de Anna } \\
\text { Luisa Santos, in Alves } 2019 .\end{array}$ \\
\hline
\end{tabular}

Elaboração própria dos autores.

Esse quadro apresenta um conjunto sistematizado de alternativas e proposições políticas para fazer frente à escassez hídrica produzida por políticas neoliberais, que foram recomendadas pelo debate público multissetorial sobre essa questão.

No entanto, acreditamos que, sem o posicionamento e o engajamento crítico e criativo da sociedade civil organizada e das instituições públicas educacionais na defesa da natureza, as políticas públicas tendem ao fracasso, principalmente quando essas estão mais voltadas para atender aos interesses privados e mercantis e não estão voltadas para atender aos interesses públicos e ao bem comum, pois os rios e as florestas não são mercadorias, mas bens essenciais à preservação de nossa frágil condição humana.

\section{Considerações Finais}

Como foi possível observar, o processo de escassez hídrica para a população, sobretudo periférica da cidade do Rio de Janeiro e entorno metropolitano, é histórico, causado por uma complexidade de fatores ambientais, políticos e econômicos e está em um ritmo de agravamento cada vez mais intenso.

As crises hídricas vêm se tornando mais frequentes, ratificando a perspectiva de avanço do processo de escassez. Esse contexto, caso seja entendido em conjunto às projeções trazidas por estudos das mudanças climáticas e à intensificação dos impactos e conflitos oriundos das formas e dinâmicas do uso e ocupação do solo da civilização moderna, indica perspectivas sobre colapso da segurança hídrica da Região Metropolitana do Rio de Janeiro.

A solução dos problemas de abastecimento público da Região Metropolitana do Rio de Janeiro vai depender da execução de projetos técnicos para transposição de águas poluídas, oriundas 
do Rio Paraíba do Sul, que fornece aproximadamente $80 \%$ da atual vazão do Rio Guandu. Essa é uma situação muito preocupante, devido a dois motivos: o primeiro se refere a essa água que abastece a Região Metropolitana do Rio de Janeiro, que precisa ser despoluída; o segundo advém do conflito sobre a captação e a transposição das águas do Paraíba do Sul, pois os governos do Rio de Janeiro e de São Paulo disputam essa captação.

A diminuição volumétrica da vazão do Rio Paraíba do Sul, evidenciada durante os anos 2013 e 2015 , contribuiu para redução progressiva da qualidade da água. Se as atividades industriais e as ocupações domiciliares continuarem crescendo e despejando dejetos na rede hidrográfica, o tratamento da água pela Companhia Estadual de Águas e Esgotos do Rio de Janeiro se tornará cada vez mais custoso. Além disso, também poderá gerar um complicado conflito político, ao mesmo tempo intermunicipal e interestadual, sobretudo entre os municípios da Região Metropolitana do Rio de Janeiro e do Vale do Paraíba, tanto do Estado do Rio de Janeiro como também de São Paulo e Minas Gerais, que pode chegar à situação de perda ou diminuição da vazão do Paraíba do Sul.

Há um eminente risco de uma catástrofe ambiental nesse rio, devido a uma montanha de escória (resíduo industrial) localizada próximo ao seu leito no município de Volta Redonda ${ }^{83}$. A contaminação proveniente deste resíduo industrial inviabilizará o abastecimento público da água transposta para o Rio Guandu por tempo indeterminado.

Entende-se, assim, que as crises hídricas percebidas na Região Metropolitana do Rio de Janeiro possuem como ponto central a combinação de quatro variáveis principais: a média de precipitação, o volume hídrico das vazões, a logística de distribuição e os conflitos de uso da água pelas múltiplas demandas.

Os estudos sobre as mudanças climáticas sugerem alterações importantes no regime pluviométrico, com aumento dos períodos de estiagem, principalmente no Continente Sulamericano, caso a temperatura média do planeta ultrapasse $2^{\circ} \mathrm{C}$. Se as pesquisas nessa linha estão corretas, as vazões médias, principalmente do Paraíba do Sul, irão diminuir, o que acarretará a intensificação dos conflitos sobre os múltiplos usos da água.

Vale ressaltar, que as intensificações dos conflitos pelo controle dos recursos hídricos já estão em curso e se configuram nas pressões existentes pela privatização e consequente transformação desse bem comum em mercadoria, as iniciativas recentes de privatização da Companhia Estadual de Águas e Esgotos do Rio de Janeiro demonstram isso.

O sistema de abastecimento do sistema Guandu opera com déficit hídrico ${ }^{84}$, mesmo quando um município possui o abastecimento público classificado como satisfatório, pois não é garantido o acesso à rede de serviço da Companhia Estadual de Águas e Esgotos do Rio de Janeiro à totalidade da sua população; ou seja, milhões de pessoas ainda não possuem acesso ao abastecimento público regular enquanto centenas de indústrias não sofrem desse problema, fato

\footnotetext{
${ }^{83}$ Conferir reportagem publicada em 28 de março de 2019, no Portal São Fidélis Notícias (SFNotícias)

$<$ https://sfnoticias.com.br/risco-ao-paraiba-do-sul-csn-e-multada-por-nao-reduzir-pilhas-de-escoria-as-margensdo-rio $>$.

${ }^{84}$ Conforme Britto et al. 2016, p. 199: “o Sistema Integrado Guandu/Lajes/Acari, que abastece o oeste metropolitano, produz a vazão total de $52.400 \mathrm{l} / \mathrm{s}$, dos quais $45.000 \mathrm{l} / \mathrm{s}$ são provenientes da ETA Guandu, 5.500 1/s do Reservatório de Lajes e 1.900 1/s do Sistema Acari. A demanda atual (2015) é da ordem de 56.000 1/s, o que indica que o sistema produtor já opera com um déficit estimado em 3.600 1/s. Para o horizonte de 2035 a demanda do sistema alcançará o valor de 73.200 1/s, no cenário tendencial, ou seja, nos padrões atuais de consumo".
} 
que indica um uso proporcional relativamente maior por parte do setor industrial do que à demanda atendida pelo abastecimento público.

Estudos sobre as condições na bacia do Rio Guandu apontavam elevado grau de comprometimento da disponibilidade hídrica para o atendimento das demandas futuras da Região Metropolitana do Rio de Janeiro. Isso nos alerta sobre a importância de se assegurar as "atuais regras operativas dos reservatórios da bacia do Rio Paraíba do Sul, indicando, principalmente, que seja alterada a atual prioridade dada à produção de energia elétrica" ${ }^{85}$, voltada preferencialmente para o setor industrial. Portanto, no contexto atual, é importante considerar que os rios Paraíba do Sul e Guandu percorrem uma região que corre risco de ser afetada por eventos de seca e, por isso, seus reservatórios deveriam ser supervisionados e geridos para garantir reservas de água para atender o abastecimento público.

A crescente pressão sobre os recursos hídricos é uma questão de grande relevância para a compreensão do atual contexto. A elevação do nível de vida da população vem, com efeito, acompanhada pelo aumento do uso per capita de água ${ }^{86}$.

A privatização não possibilita ganho econômico para os municípios, já que os mesmos não terão atribuição de distribuição e cobrança sobre a água. A única garantia que os municípios possuem, até o momento, é a esperança de terem seus problemas de abastecimento de água e saneamento sanados. Essa situação evidencia as influências perversas da lógica neoliberal dos interesses econômicos presentes na Região Metropolitana do Rio de Janeiro.

Essas influências mercantilistas, no contexto do fornecimento da água na Região Metropolitana do Rio de Janeiro, estão sendo alimentadas pelo setor industrial de commodities, principalmente os presentes na Região Hidrográfica da Baía de Sepetiba.

Assim, entende-se que o poder público não se constitui como o principal condutor do projeto desenvolvimentista do território do estado, ou seja, será que as instituições que atuam sob seu comando conseguirão atender as demandas e os desafios que as cidades no futuro exigirão? ${ }^{87}$.

Para concluir, as questões que ficam são as seguintes: 1. Qual será o limite de saturação para tratamento da água poluída que abastece a Região Metropolitana do Rio de Janeiro, ou seja, até que ponto será possível tratá-la? 2. Caso a transposição do Paraíba do Sul cesse ou diminua substancialmente o fornecimento de água para o Sistema Guandu, como será realizado o abastecimento público da Região Metropolitana do Rio de Janeiro? 3. Caso diminua o volume hídrico transposto, quais atores sociais serão os prejudicados pela escassez hídrica na Região Metropolitana do Rio de Janeiro? 4. Quais áreas e setores serão priorizados para receber o serviço de abastecimento público? 5. Como a concessão da Companhia Estadual de Águas e Esgotos do Rio de Janeiro, caso realmente isso ocorra, irá lidar com as consequências de um possível e provável colapso hídrico do abastecimento público da Região Metropolitana do Rio de Janeiro?

\footnotetext{
${ }^{85}$ Cf. Britto et al. 2016.

${ }^{86}$ Segundo Cinco 2016, p. 21: Mas, a água não possui "uso exclusivamente residencial; além de ser distribuída para as residências, é também para o comércio, setor de serviços, megaequipamentos urbanos - incluindo alguns grandes usuários de água, tais como hotéis, escolas, hospitais, restaurantes, shoppings e até mesmo para algumas indústrias".

${ }^{87}$ Cf. Britto et al. 2016.
} 


\section{Referências bibliográficas}

ABREU, Mauricio de Almeida. A cidade, a montanha e a floresta. In: ABREU, Mauricio de Almeida. (Org.). Natureza e sociedade no Rio de Janeiro. Prefeitura da Cidade do Rio de Janeiro, Rio de Janeiro, 1992, p. 54-103.

AGEVAP. Plano Estratégico de Recursos Hídricos das Bacias Hidrográficas dos Rios Guandu, da Guarda e Guandu Mirim - Relatório de Diagnóstico da Região Hidrográfica II. Rio de Janeiro: Agência da Bacia do Rio Paraíba do Sul (AGEVAP) / Comitê da Bacia Hidrográfica $\begin{array}{llll}\text { do Rio } & \text { Guandu } & 2017\end{array}$ <http://sigaceivap.org.br:8080/publicacoesArquivos/guandu/arq_pubMidia_Processo_0632013_P2TOMOII.pdf> [Consulta: 20/04/2020].

ALVES, Alan Tiago. Estudante da BA cria tecnologia para filtrar água através da luz solar em regiões do semiárido e leva prêmio nos EUA. G1 BA, 2019 <https://g1.globo.com/ba/bahia/noticia/2019/04/17/estudante-da-ba-cria-tecnologia-parafiltrar-agua-atraves-da-luz-solar-em-regioes-do-semiarido-e-leva-premio-nos-eua.ghtml >

ANELLI, Renato. L. S. Uma Nova Cidade para as Águas Urbanas, Estudos Avançados, v. 29, $\mathrm{n}^{\circ} \quad 84, \quad 2015 . \quad$ p. $\quad 69-84 \quad<$ https://www.scielo.br/scielo.php?pid=S010340142015000200069\&script=sci_arttext $>$ [Consulta: 20/04/2020].

ARAÚJO, Alexandre. Mudanças Climáticas e água: de crise ao colapso. Crise Hídrica em $\begin{array}{llllll}\text { Debate. Rio de Janeiro: } & \text { NPC, }\end{array}$ <https://www.researchgate.net/publication/317673072>.

AZPIAZU, Daniel e CASTRO, José. E. Águas públicas: Lições de Buenos Aires. Crise Hídrica em Debate. Rio de Janeiro: NPC, 2016, p.175-194 <https://www.researchgate.net/publication/317673072>.

BITTENCOURT, Carlos; SERAFINI, Flavio. A crise não é da água, mas da sociedade. Breve análise sobre a situação do Rio de Janeiro. Crise Hídrica em Debate. Rio de Janeiro: NPC, 2016, p. 83-92 <https://www.researchgate.net/publication/317673072>.

BRANCO, Otavio Eurico de Aquino. Avaliação da disponibilidade hídrica: Conceitos e aplicabilidade. Universidade Federal de Juiz de Fora, Curso de Engenharia Ambiental, 2006 <http://www.ufjf.br/engsanitariaeambiental/files/2012/04/Disponibilidade-

H\%25C3\%25ADdrica.pdf> [Consulta: 19/04/2020].

BRITTO, Ana Lucia; FORMIGA JOHNSSON, Rosa Maria; CARNEIRO, Paulo Roberto Ferreira. Abastecimento público e escassez hidrossocial na metrópole do Rio de Janeiro. Ambiente \& Sociedade, São Paulo: Associação Nacional de Pós-Graduação e Pesquisa em Ambiente e Sociedade, Vol. XIX, n. 1, p. 185-208, jan-mar, 2016 <https://www.scielo.br/pdf/asoc/v19n1/pt_1809-4422-asoc-19-01-00183.pdf> [Consulta: 10/02/2020].

BUCKERIDGE, Marcos. Árvores Urbanas em São Paulo: Planejamento Economia e Água. Estudos Avançados, $\quad$ v. 29, $\mathrm{n}^{\circ} \quad 84, \quad$ São Paulo, $2015 . \quad$ p. 85-101 
<https://www.scielo.br/scielo.php?pid=S0103-40142015000200085\&script=sci_arttext $>$

[Consulta: 20/04/2020].

BUCKERIDGE, Marcos; RIBEIRO, Wagner Costa (Coords.). Livro branco da água. A crise hídrica na Região Metropolitana de São Paulo em 2013-2015: Origens, impactos e soluções. São Paulo: Instituto de Estudos Avançados, 2018. <http://www.iea.usp.br/publicacoes/ebooks/livro-branco-da-agua/at_download/file> [Consulta: 20/04/2020].

CAMPOS, Julyenne. M.; ROSTON, Denis M.; QUEIROZ, Sônia C. N. Desenvolvimento e validação de método para determinação de bisfenol a e etinilestradiol em aguapé e mini-papiro provenientes de wetlands construídas. Química nova, vol.42 (8), 2019. p. 920-927. $<$ https://www.scielo.br/scielo.php?pid=S0100-

40422019004800920\&script=sci_arttext\&tlng=pt $>$ [Consulta: 20/04/2020].

CAPEL, Horacio. El agua como servicio público. A propósito del Seminario Internacional Faire Parler les Reseaux: L'eau, Europe-Amérique Latine. Biblio 3W. Revista Bibliográfica de Geografía y Ciencias Sociales. Universidad de Barcelona, No 218, 22 de marzo de 2000. <http://www.ub.edu/geocrit/b3w-218.htm>.

CARNEIRO, Paulo Roberto Ferreira. Crise e segurança hídrica na região metropolitana do Rio de Janeiro. Crise Hídrica em Debate. Rio de Janeiro: NPC, 2016, p. 71-82 $<$ https://www.researchgate.net/publication/317673072>.

CASTRO, Cléber Marques;FERREIRINHA, Mariane Motta. A Problemática Ambiental na Bacia Hidrográfica do Rio Guandu: Desafios para a Gestão dos Recursos Hídricos. Anuário do $\begin{array}{llllll}\text { Instituto de Geociências, } & \text { 2012, } & \text { Vol } & 35, & \text { p. }\end{array}$ <http://www.ppegeo.igc.usp.br/index.php/anigeo/article/view/5953> [Consulta:7/04/2020].

CINCO, Renato Athayde Silva. Notas da Presidência da Comissão Especial sobre o Colapso Hídrico. In: Crise Hídrica em Debate. Rio de Janeiro: NPC, 2016, p.17-55 <https://www.researchgate.net/publication/317673072>.

COSTA, Maria Angélica Maciel. Os fluxos da água na metrópole: usos múltiplos e gestão participativa na Baía de Guanabara (RJ). Tese (doutorado). Universidade Federal do Rio de Janeiro, Instituto de Pesquisa e Planejamento Urbano e Regional - IPPUR/UFRJ, 2013 <http://objdig.ufrj.br/42/teses/810657.pdf>.

COUTINHO, Priscila E. Avaliação da disponibilidade hídrica dos próximos cem anos para a bacia do rio Tietê, com base nos cenários do IPCC. Trabalho de Conclusão de Curso (Bacharelado em Engenharia de Recursos Hídricos e do Meio Ambiente), Escola de Engenharia, Universidade Federal Fluminense, Niterói, 2019. <https://app.uff.br/riuff/handle/1/12285> [Consulta: 20/04/2020].

CÂMARA MUNICIPAL DO RIO DE JANEIRO. Comissão Especial sobre o Colapso Hídrico. Crise hídrica em debate (CHD). Rio de Janeiro: Editora NPC, 2016 <https://www.researchgate.net/publication/317673072>.

DERTONI, Marcos de Macedo; TEIXEIRA, Claudia Silva; ARAÚJO, Luiz Felipe Brito de; HEIDERICH, Aline de Souza (Coords.). Obras de Proteção da Tomada D'água da CEDAE no 
Rio Guandu: Relatório de Impacto Ambiental - RIMA. Rio de Janeiro, 2011 <http://www.ceivap.org.br/downloads2011/CEDAE_RIMA.pdf>.

DIAS, Alexandre Pessoa Dias; DIEILE DA SILVA, Bianca. Saneamento, saúde e direitos humanos: as iniquidades socioambientais e a luta pela água na Cidade do Rio de Janeiro. Crise Hídrica em Debate. Rio de Janeiro: NPC, 2016, p. 93-112 <https://www.researchgate.net/publication/317673072>.

EMPINOTTI, Vanessa Lucena; JACOBI, Pedro Roberto e FRACALANZA, Ana Paula. Transparência e a governança das águas. São Paulo: Estudos Avançados, 30 (88), 2016 <https://www.revistas.usp.br/eav/article/view/124267/120590>ＤOI: $\quad 10.1590 /$ S010340142016.30880006 .

FARIA, Edimur Ferreira de; ROCHA, Rogéria Mara Lopes; GOMES, Isabella Monteiro. Os desafios da integração da gestão ambiental com a gestão de recursos hídricos. Anais do Congresso Nacional do CONPEDI. Belo Horizonte, 2008, p. 4275-4291 $<$ http://www.publicadireito.com.br/conpedi/manaus/arquivos/anais/bh/edimur_ferreira_de_far ia2.pdf> [Consulta: 19/04/2020].

FEARNSIDE, Philip. Rios voadores e a água de São Paulo 1: A questão levantada. Amazônia Real, 2015, p. 1-3 <http://philip.inpa.gov.br/publ_restritas/2015/Rios_voadoresS\%C3\%A9rie_completa.pdf> [Consulta: 06/03/2020].

FULFORD, Galen; SHAW, Michael; SHAW, Lisa. Re-Imagining the Garden City. Biomatrix Water, Scotland, $2008<$ https://www.biomatrixwater.com/uncategorized/re-imagining-thegarden-city/?preview=true\&_thumbnail_id=1609> [Consulta: 20/04/2020].

GIROTA, Ary. O colapso hídrico no Rio de janeiro e o papel central da Cedae enquanto empresa estatal de saneamento para atenuar os efeitos desta crise. Crise Hídrica em Debate. $\begin{array}{llllll}\text { Rio de } & \text { Janeiro: 205-214 }\end{array}$ $<$ https://www.researchgate.net/publication/317673072>.

GUANDU. Relatório do Guinness Book, o Livro dos Recordes. Rio de Janeiro: CEDAE, 2007 <https://www.cedae.com.br/portals/0/livreto_guandu.pdf>.

GUSMÃO, Paulo. Apropriação e ordenamento territorial na zona costeira no estado do rio de janeiro. grandes corporações ou as políticas públicas? Estudos Urbanos e Regionais, 2010, vol. 12, p. 23-37 <https://rbeur.anpur.org.br/rbeur/article/view/251> [Consulta: 5/03/2020].

HARVEY, David. O enigma do capital e as crises do capitalismo. São Paulo: Boitempo, 2011.

HESPANHOL, Ivanildo. Conservação e reuso como instrumentos de gestão para atenuar os custos de cobrança pelo uso de água no setor industrial. In: BICUDO C.; TUNDISI J. G.; SCHEUENSTUHL, M. Águas do Brasil. Análises Estratégicas. Academia Brasileira de Ciências, Instituto de Botânica, 2010, p. 59-80 <http://docplayer.com.br/7940013Conservacao-e-reuso-como-instrumentos-de-gestao-para-atenuar-os-custos-de-cobranca-pelouso-da-agua-no-setor-industrial.html> [Consulta: 20/04/2020]. 
HUPFER, H. M.; FIQUEIREDO, J. A. S.; TUNDISI J. G. (Orgs.). Pagamento por Serviços Ambientais. Porto Alegre, Entremeios, 2013.

INEA. Instituto Estadual do Ambiente (RJ). Base legal para a gestão das águas do Estado do Rio de Janeiro (1997- 2018). Lívia Soalheiro e Romano et al. (Org.). $4^{\mathrm{a}}$ ed. rev. ampl. Rio de Janeiro, 2019. <http://www.inea.rj.gov.br/wp-content/uploads/2019/03/baseLegal_4aedicao_INTERATIVO.pdf> [Consulta: 20/04/2020].

INEA. Instituto Estadual do Ambiente (RJ). Atlas dos mananciais de abastecimento público do Estado do Rio de Janeiro: subsídios ao planejamento e ordenamento territorial. Silvia Marie Ikemoto (Coordenação geral); Patrícia Rosa Martines Napoleão (Coordenação executiva). Rio de Janeiro, 2018. <http://www.inea.rj.gov.br/wp-content/uploads/2019/01/Livro_Atlas-dosMananciais-de-Abastecimento-do-Estado-do-Rio-de-Janeiro.pdf> [Consulta: 20/04/2020].

JARAMILLO, Fernando; DESTOUNI, Geórgia. Freshwater consumption has already crossed $\begin{array}{llll}\text { the globalfreshwater planetary boundary. } & \text { Science, } 2015\end{array}$ <https://www.sciencedaily.com/releases/2015/06/150616071910.htm>.

LAMEIRA, Ana Beatriz et al. Diagnóstico e alternativas para a recuperação ambiental da Bacia Hidrográfica do Rio Guandu (BHRG), RJ. Rio de Janeiro: Embrapa Solos, 2010 <https://www.infoteca.cnptia.embrapa.br/bitstream/doc/881979/4/documentos122.pdf>.

LE STRAT, Anne. A água em Paris: um novo serviço público. Crise Hídrica em Debate. Rio de Janeiro: NPC, 2016, p. 195-204 <https://www.researchgate.net/publication/317673072>.

LÖWY, Michael. A alternativa Ecossocialista. Crise Hídrica em Debate. Rio de Janeiro: NPC, 2016, p. 145-150<https://www.researchgate.net/publication/317673072>.

MAGAlHÃES, Paulo Canedo (Coord.). Plano de Recursos Hídricos para a Fase Inicial da Cobrança na Bacia do Rio Paraíba do Sul (PGRH-RE-010-R0), Vol. 3. Rio de Janeiro: ANA / COPPETEC,

2002

$<$ https://www.ana.gov.br/acoesadministrativas/ContratosConvenios/_docs/019_2001/pgrh-re010/pgrh-re-010-r0-vol3.pdf>.

MARCH, Hug y SAURÍ, David. Flujos de Agua, Flujos de Capital: Sistemas de Abastecimiento y Gobernanza del Agua en Madrid y Barcelona. Investigaciones Geográficas, Universidad de Alicante: Instituto Interuniversitario de Geografía. $\mathrm{n}^{\mathrm{o}} 51 \quad$ (2010) p. $7-26$ <https://www.redalyc.org/pdf/176/17618736001.pdf>.

MARQUES, Luiz. Capitalismo e colapso ambiental. São Paulo: Editora Unicamp, 2018.

MCDOWALL, Duncan. Light: a história da empresa que modernizou o Brasil. Rio de Janeiro: Ediouro, 2008.

MELO, João Alfredo Telles; MARQUES, Geovana Oliveira Patrício. Água -direito humano fundamental e bem comum- e as mudanças climáticas. Crise Hídrica em Debate. Rio de Janeiro: NPC, 2016, p. 119-136 <https://www.researchgate.net/publication/317673072>.

BERNSTEIN, Any; NUNES, Ueslei Marcos; NÓVOA DA SILVA, Cláudia Conceição; COUTO, Daise Vieira Silva. Sudeste rumo à Desertificação: Rio Paraíba do Sul. Educação 
Pública CAPES, 2015 <https://educacaopublica.cecierj.edu.br/artigos/15/15/sudeste-rumodesertificao-rio-paraba-do-sul> [Consulta: 14/03/2020].

OGASHAWARA, Igor; ALCÂNTARA, Enner H; STECH, José L.; TUNDISI, José. G. Cyanobacteria Detection in Guarapiranga Reservoir (S. Paulo-Brazil) Using Landsat T. M. and ETM Images. Ambiente \& Água, v. 9, n. 2. Taubaté, 2014, p. 1-14. <https://www.scielo.br/scielo.php?pid=S1980-993X2014000200005\&script=sci_arttext> [Consulta: 21/04/2020].

OLIVEIRA, Oscar. O levante das águas - Os bens comuns e a visão andina da água restabelecidos pelo povo na Bolívia e nos Andes. Crise Hídrica em Debate. Rio de Janeiro: NPC, 2016, p.167-174 <https://www.researchgate.net/publication/317673072>.

OTTOBONI, Laura. Changes in the Bacterial Community of Soil from a Neutral Mine Drainage Channel. Plos One, 2014, vol, 9, $\mathrm{n}^{\circ} \quad 5$ <https://www.ncbi.nlm.nih.gov/pmc/articles/PMC4010462/> [Consulta: 18/03/2020].

PERHI-RJ. Plano Estadual de Recursos Hídricos do Estado do Rio de Janeiro. Rio de Janeiro. INEA, 2014 <http://200.20.53.26:8080/cs/idcplg?IdcService=GET_FILE\&dID=84748\&dDocName=INE A0068928\&allowInterrupt=1> [Consulta: 19/04/2020].

PIGEON, Martin. Remunicipalização em um setor vital: sistemas urbanos de água. Crise Hídrica em Debate. Rio de Janeiro: NPC, 2016, p.151-156 <https://www.researchgate.net/publication/317673072>.

PINTO, Nilza Medeiros. Rio de Janeiro, refém das águas do Guandu. Dissertação (mestrado). Universidade Federal de Ouro Preto, Departamento de Engenharia Ambiental, 2010 <http://www.dominiopublico.gov.br/pesquisa/DetalheObraForm.do?select_action=\&co_obra $=180481>$ [Consulta: 01/03/2020].

PIZELLA, Denise G. A relação entre Planos Diretores Municipais e Planos de Bacias Hidrográficas na gestão hídrica. Revista Ambiente e Água, vol 10, n 3. Taubaté, 2015. <https://www.scielo.br/scielo.php?pid=S1980-993X2015000300635\&script=sci_arttext> [Consulta: 19/04/2020].

QUEIROZ, Arlei Teodoro. Análise e avaliação da demanda e da disponibilidade hídrica nos alto e médio cursos do Rio Uberabinha e o abastecimento público em Uberlândia (MG). Dissertação (Mestrado em Ciências Humanas) - Universidade Federal de Uberlândia, Uberlândia, 2012. <http://repositorio.ufu.br/handle/123456789/16138> [Consulta: 20/04/2020].

SANTILLI, Juliana Ferraz da Rocha. A Política Nacional de Recursos Hídricos (Lei 9.433/97) e sua Implementação no Distrito Federal. Revista da Fundação Escola Superior do Ministério Público do Distrito Federal e Territórios, Brasília, Ano 9, V. 17, p. 144 - 179, jan./jun. 2001 <https://ceapg.fgv.br/sites/ceapg.fgv.br/files/u60/politica_nacional_dos_recursos_hidricos.pdf $>$. 
SANTOS, Milton. Por uma outra globalização: do pensamento único à consciência universal. Rio de Janeiro: Record, 2000.

SWYNGEDOUW, Erik. The Antinomies of the Postpolitical City: In Search of a Democratic Politics of Environmental Production. International Journal of Urban and Regional Research, 2009, vol 33, n³, p. 601-617 <https://onlinelibrary.wiley.com/doi/epdf/10.1111/j.14682427.2009.00859.x> [Consulta: 15/03/2020].

TUBBS FILHO, Décio; ANTUNES, Júlio Cesar Oliveira; SILVA VETTORAZZI, Janaina (Org.). Bacia Hidrográfica dos Rios Guandu, da Guarda e Guandu-Mirim/Comitê da Bacia Hidrográfica Guandu (CBHG). Rio de Janeiro: INEA, $2012<$ http://www.inea.rj.gov.br/wpcontent/uploads/2019/01/Livro_Bacia-Hidrogr\%C3\%A1fica-dos-Rios-Guandu-da-Guarda-eGuandu-Mirim.pdf> [Consulta: 20/04/2020].

TUNDISI, José Galizia; TUNDISI, Takako Matsumura. As múltiplas dimensões da crise hídrica. Revista USP, 2015, $\quad \mathrm{n}^{\circ} \quad 106, \quad$ p. 21-30 <https://www.revistas.usp.br/revusp/article/view/109780/108286> [Consulta: 05/03/2020].

VERRAN, Miguel. G. Ecotelhados: alternativas de uso da vegetação no ambiente urbano. Trabalho de conclusão de curso. (Graduação em Agronomia), Universidade Federal do Rio Grande do Sul. Faculdade de Agronomia, 2015. <https://www.lume.ufrgs.br/handle/10183/150979> [Consulta: 19/04/2020].

VOLSCHAN JR, Isaac. Causa e efeitos da poluição por esgotos sanitários e a crise do abastecimento de água da Região Metropolitana do Rio de Janeiro. Rio de Janeiro: Plural, 16 de janeiro de $2020 \quad<$ https://www.plurale.com.br/site/noticiasdetalhes.php? $\operatorname{cod}=17303 \& \operatorname{cod} S e c a 0=11 \&$ oMnu=especiais $\&$ sub=agua $>\quad$ [Consulta: 20/04/2020]

YOUNG, Gordon; DEMUTH, Siegrifild; MISHIRA, Anil; CUDENNEC, Christophe. Hydrological Challenges and Water Security: An Overview. Hydrological Sciences and Water Security: Past, Present and Future. Proceedings of the 22th FOUACS Collegium. Paris, IHHS Publ., 2015 ,

p.

2-9

$<$ https://www.researchgate.net/publication/276901530_Hydrological_sciences_and_water_se curity_An_overview/fulltext/59de1a8da6fdccc2e0f4f13b/Hydrological-sciences-and-watersecurity-An-overview.pdf?origin=publication_detail> [Consulta: 20/04/2020].

ZAAR, Miriam Hermi. Cambio climático antropogénico y decrecimiento.Ar@cne.Revista Electrónica de Recursos de Internet sobre Geografía y Ciencias Sociales. Barcelona: Universidad de Barcelona, 1 de enero de 2021, vol. XXV, $\mathrm{n}^{\circ}$ 250. DOI: <https://doi.org/10.1344/ara2021.250.33232>.

Ficha bibliográfica:

PIRES, Hindenburgo Francisco; CERQUEIRA, Danilo Rocha. Alternativas à escassez e a crise hídrica produzidas por políticas neoliberais no Rio de Janeiro. Ar@cne. Revista Electrónica de Recursos de Internet sobre Geografia y Ciencias Sociales. Barcelona: Universidad de Barcelona, I de julio de 202I, vol. XXV, $n^{\circ}$ 256. DOI: https://doi.org/I0.1344/ara202I.256.35476 